\title{
La fisica degli acceleratori di particelle
}

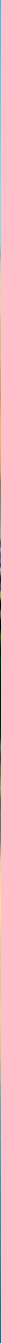

Istituto Nazionale di Fisica Nucleare

Laboratori Nazionali di Frascati

6 novembre 2020

Www.Inf.infn.it/edu/incontri/2020

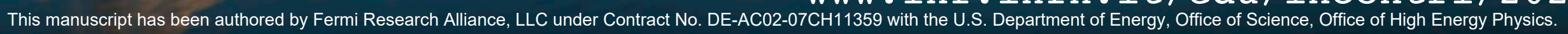




\section{Struttura dell'incontro di oggi}

- Considerazioni generali

- Concetti fondamentali

- Evoluzione storica

- Applicazioni

- Spunti per la didattica

- Risorse per approfondire

Faremo un paio di pause tra gli argomenti principali e alla fine dell'incontro per domande e commenti 


\section{Perché studiare la fisica degli acceleratori?}

- Scienza: strumenti fondamentali per scoperte scientifiche in fisica nucleare e sub-nucleare, chimica, biologia, ecc.

- Applicazioni: diagnostica medica e terapie, processi industriali, tecnologie innovative

- Società: collaborazioni internazionali avvicinano persone di diverse culture

- Settore interdisciplinare: matematica, fisica, ingegneria, informatica - persone con talenti diversi possono contribuire e trovare la loro vocazione

- Sviluppo professionale: esistono ottimi corsi, tirocini e possibilità di lavoro per i giovani più promettenti 


\section{Principi e concetti fondamentali}




\section{Unità di energia}

- L'elettronvolt $(\mathrm{eV})$ è un'utile unità di energia

- È l'energia cinetica acquisita da un elettrone in una differenza di potenziale di 1 volt:

Simone l'Elettrone

$1 \mathrm{eV} \equiv q \cdot \Delta V=\left(1.602 \times 10^{-19} \mathrm{C}\right) \cdot(1 \mathrm{~V})=1.602 \times 10^{-19} \mathrm{~J}$

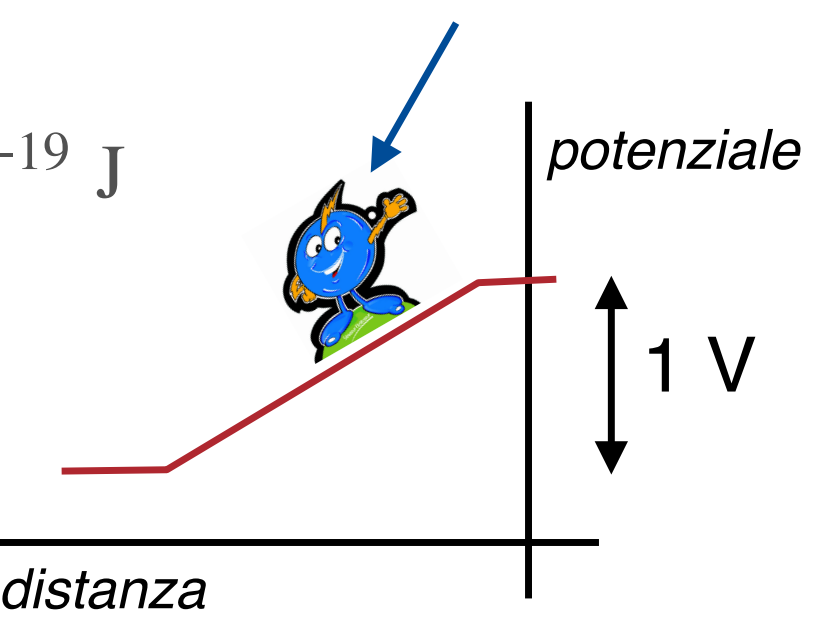

- Multipli sono il keV $\left(10^{3} \mathrm{eV}\right), \mathrm{MeV}\left(10^{6} \mathrm{eV}\right), \mathrm{GeV}\left(10^{9} \mathrm{eV}\right)$, TeV $\left(10^{12} \mathrm{eV}\right)$, ecc. 


\section{Energia: unità e ordini di grandezza}

consumo energetico annuo in Italia

$\left(10^{18} \mathrm{~J}\right)$

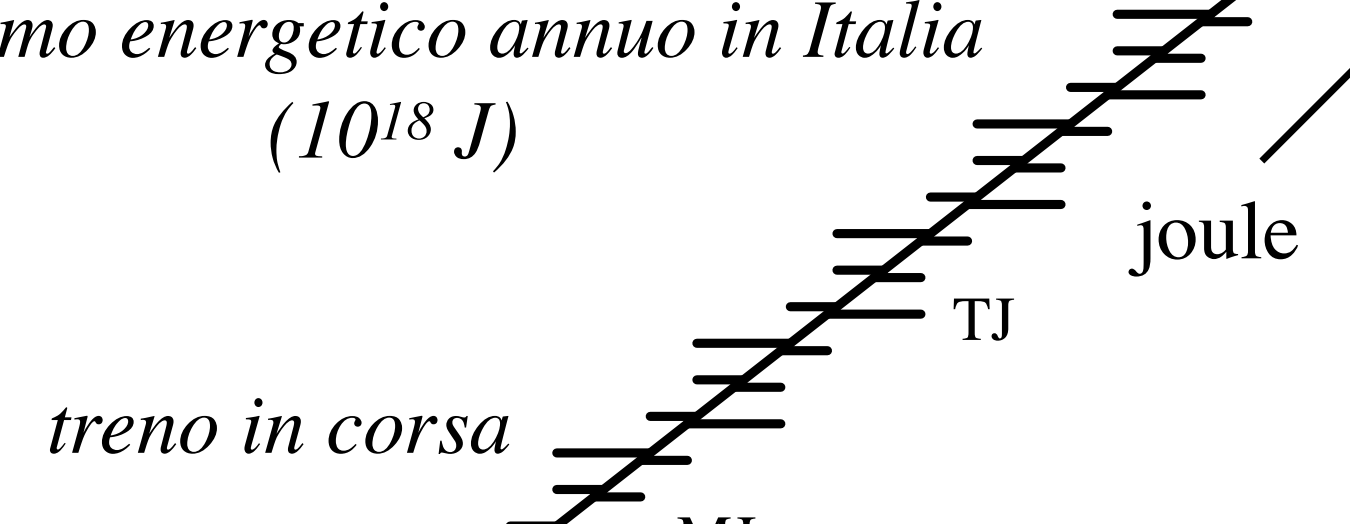

elettronvolt

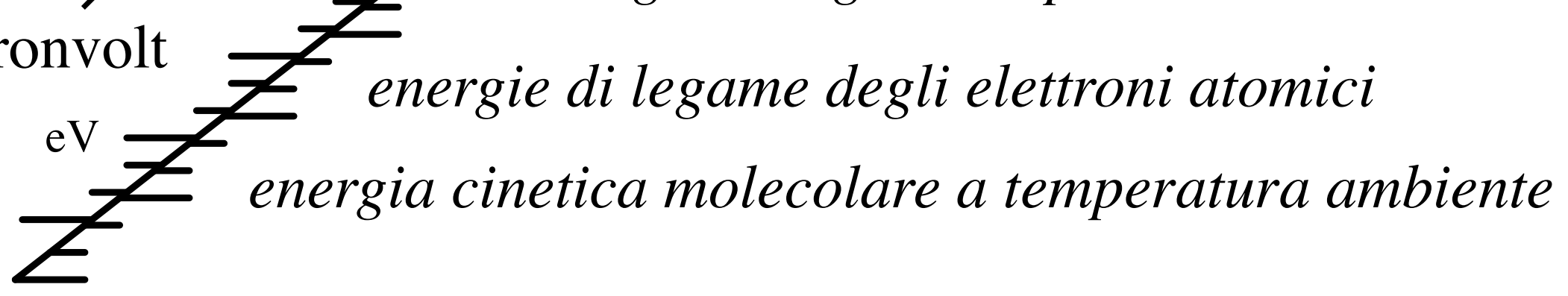

(protoni a $6.5 \mathrm{TeV}$ in $\mathrm{LHC}$ ) 


\section{Particella carica in campo elettromagnetico: forza di Lorentz}

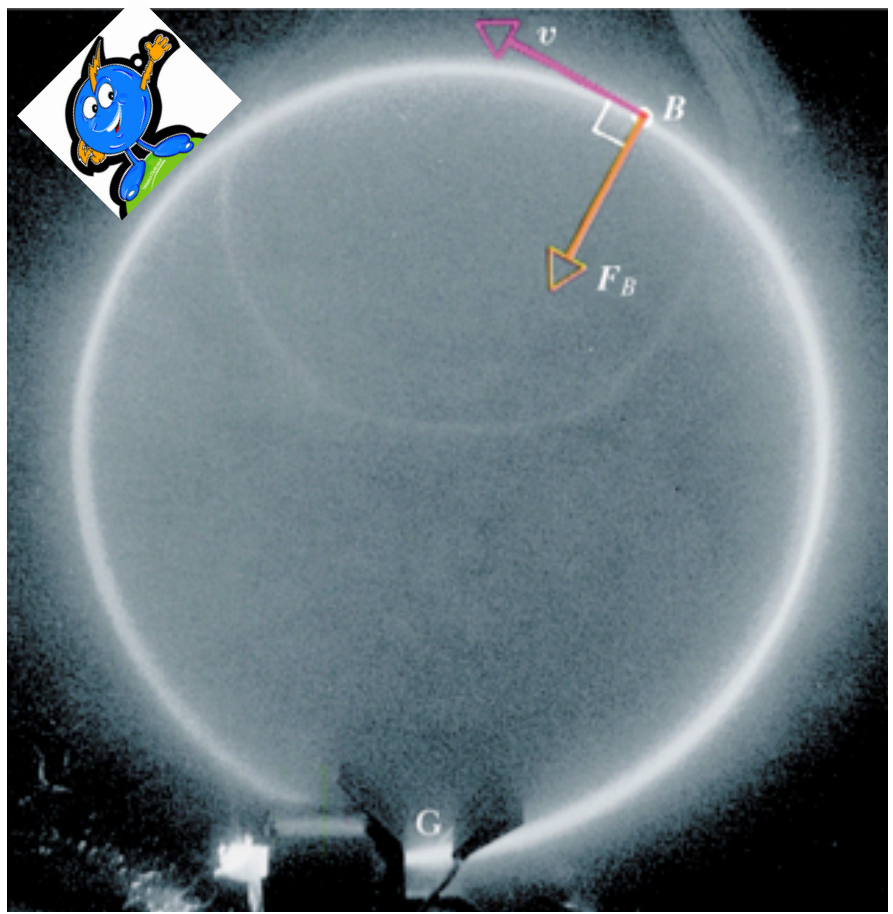

Sorgente di elettroni da $1 \mathrm{keV}$ in campo magnetico di $1 \mathrm{mT}$. Raggio di curvatura $11 \mathrm{~cm}$.

$$
\mathbf{F}=q \cdot(\mathbf{E}+\mathbf{v} \times \mathbf{B})
$$

- Campi elettrici usati per accelerare e deflettere

- Campi magnetici statici possono soltanto deflettere (forza perpendicolare alla velocità)

- Efficaci ad alte energie (forza proporzionale alla velocità)

raggio di curvatura

$$
\rho=\left(\frac{p}{q}\right) \cdot \frac{1}{B}
$$

rigidità magnetica ("B rho")

della particella: impulso / carica 


\section{Funzioni di base dei magneti}

Magnete dipolare o dipolo: "prisma magnetico", deflessione
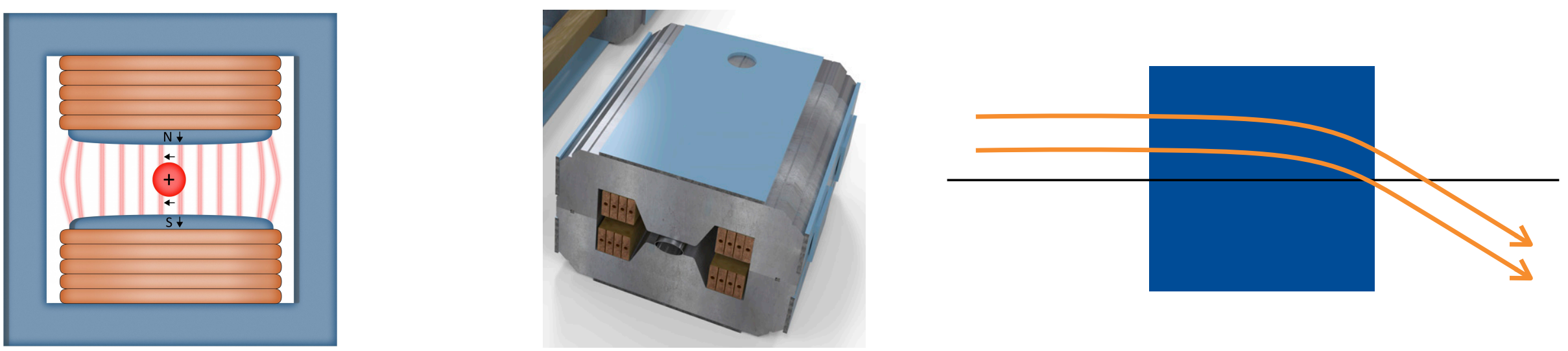

campo costante

Magnete quadrupolare o quadrupolo: "lente magnetica”, focalizzazione
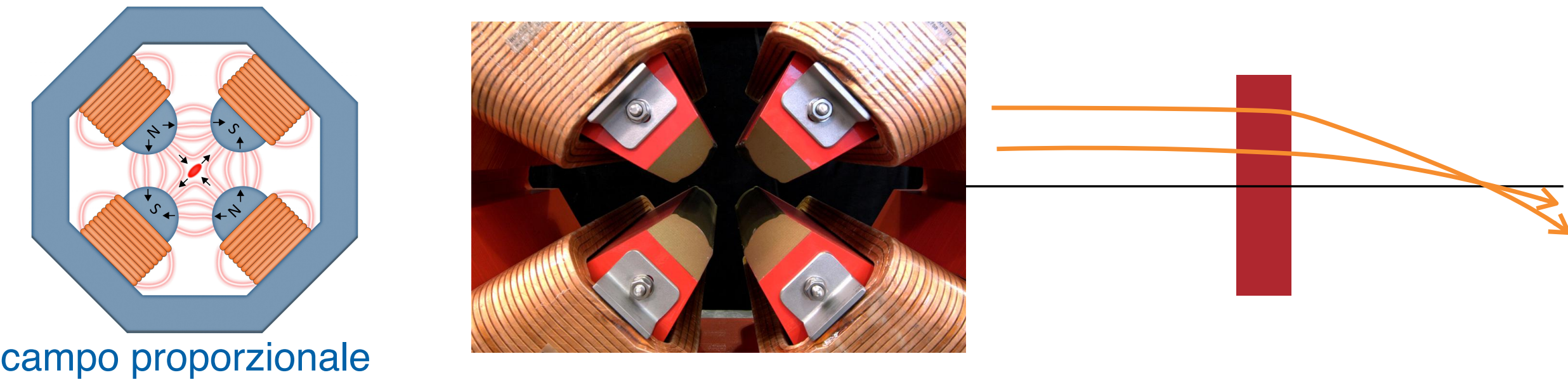
alla distanza dall'asse 


\section{Intensità, sezioni d'urto, luminosità}

Relazione essenziale per il progetto e l'analisi degli esperimenti, sia su bersaglio fisso che in movimento

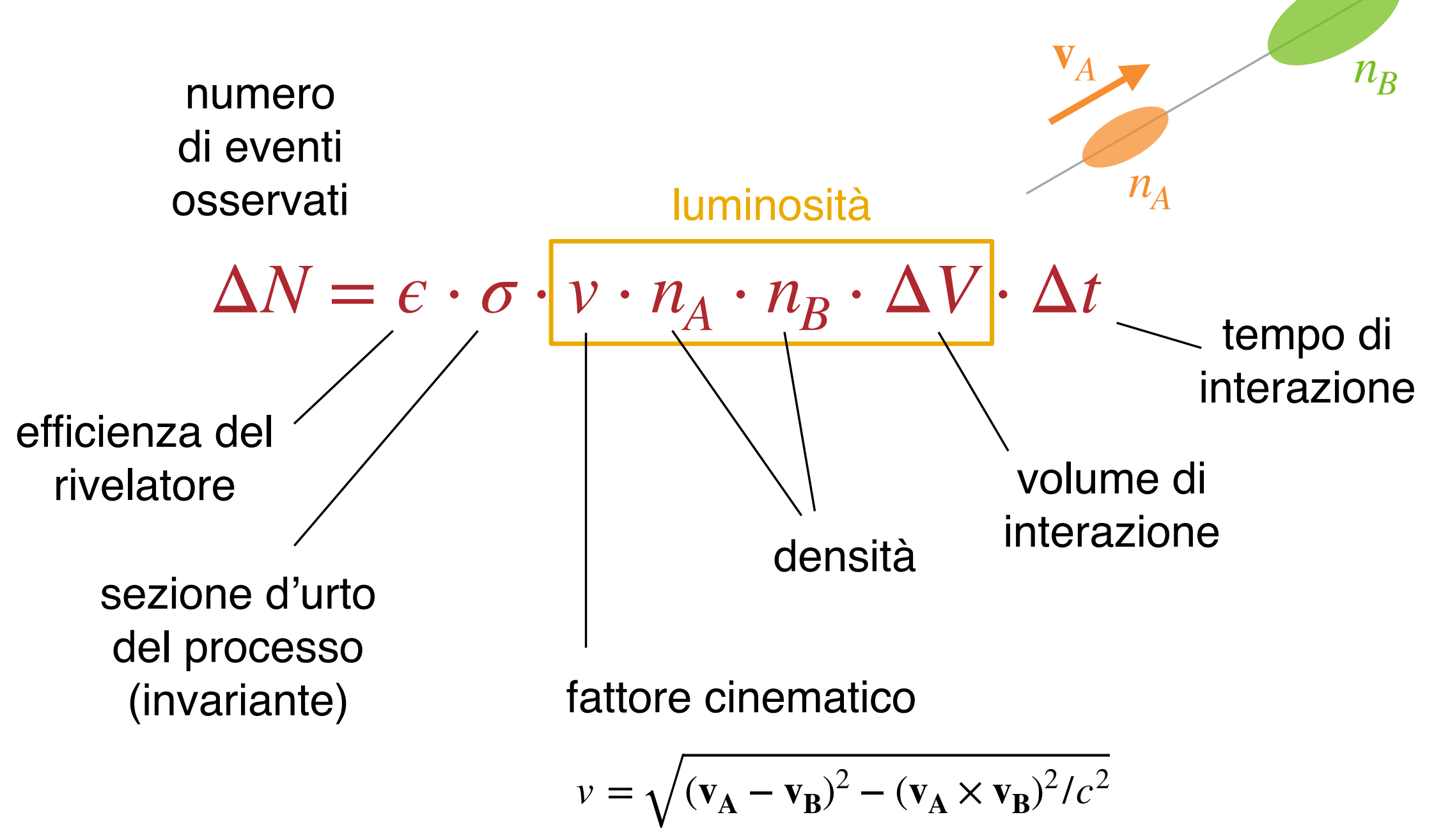




\section{Evoluzione degli acceleratori}




\section{Perché accelerare? E come?}

1. Il sorprendente fenomeno di conversione dell'energia cinetica in massa $\left(E=m c^{2}\right)$ permette di scoprire e studiare diverse forme di materia

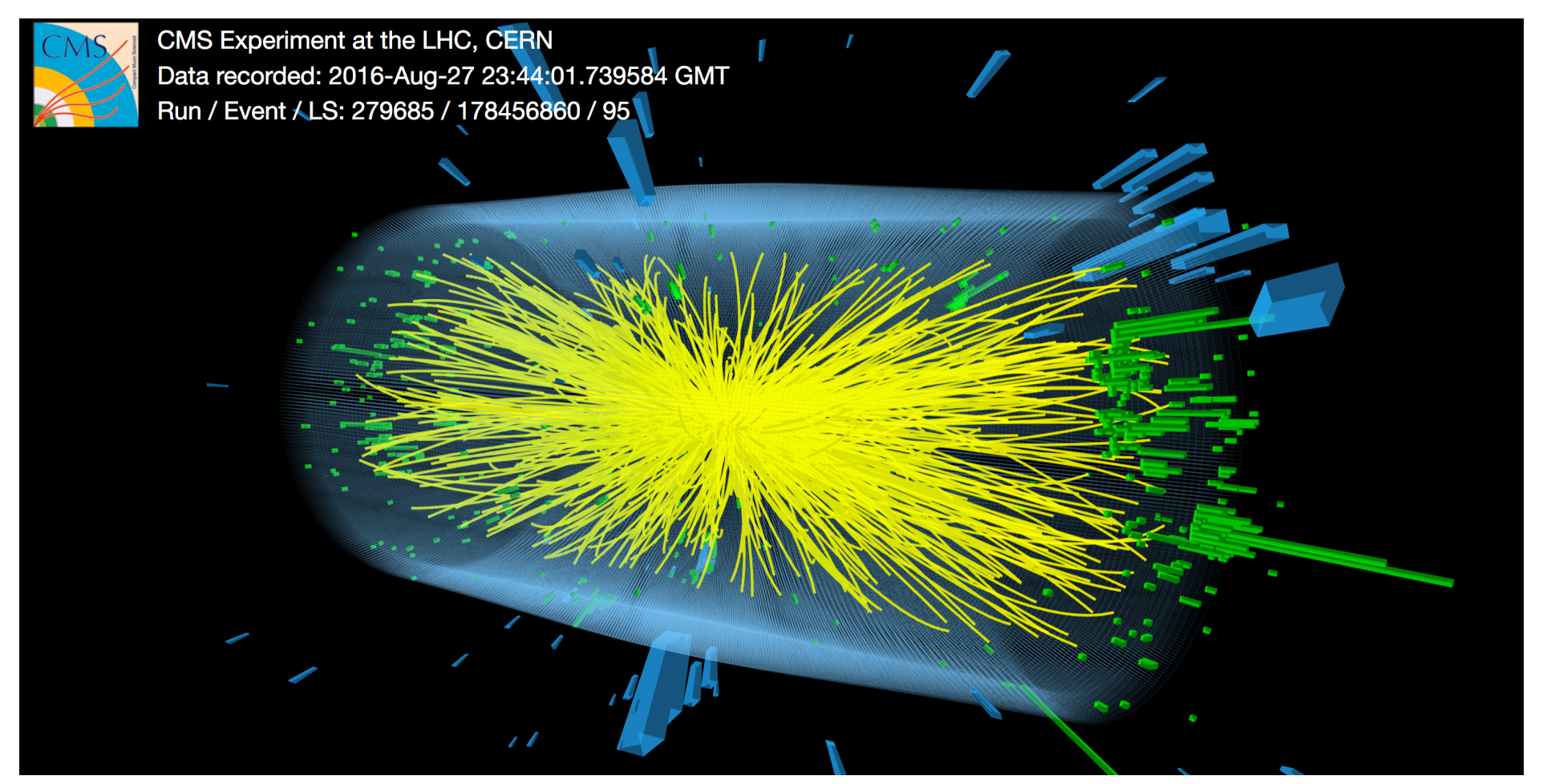




\section{Perché accelerare? E come?}

2. Fasci primari di particelle energetiche vengono utilizzati per creare fasci secondari intensi e collimati che non esistono in natura: pioni, muoni, antiprotoni, positroni, fotoni, neutrini, ecc.

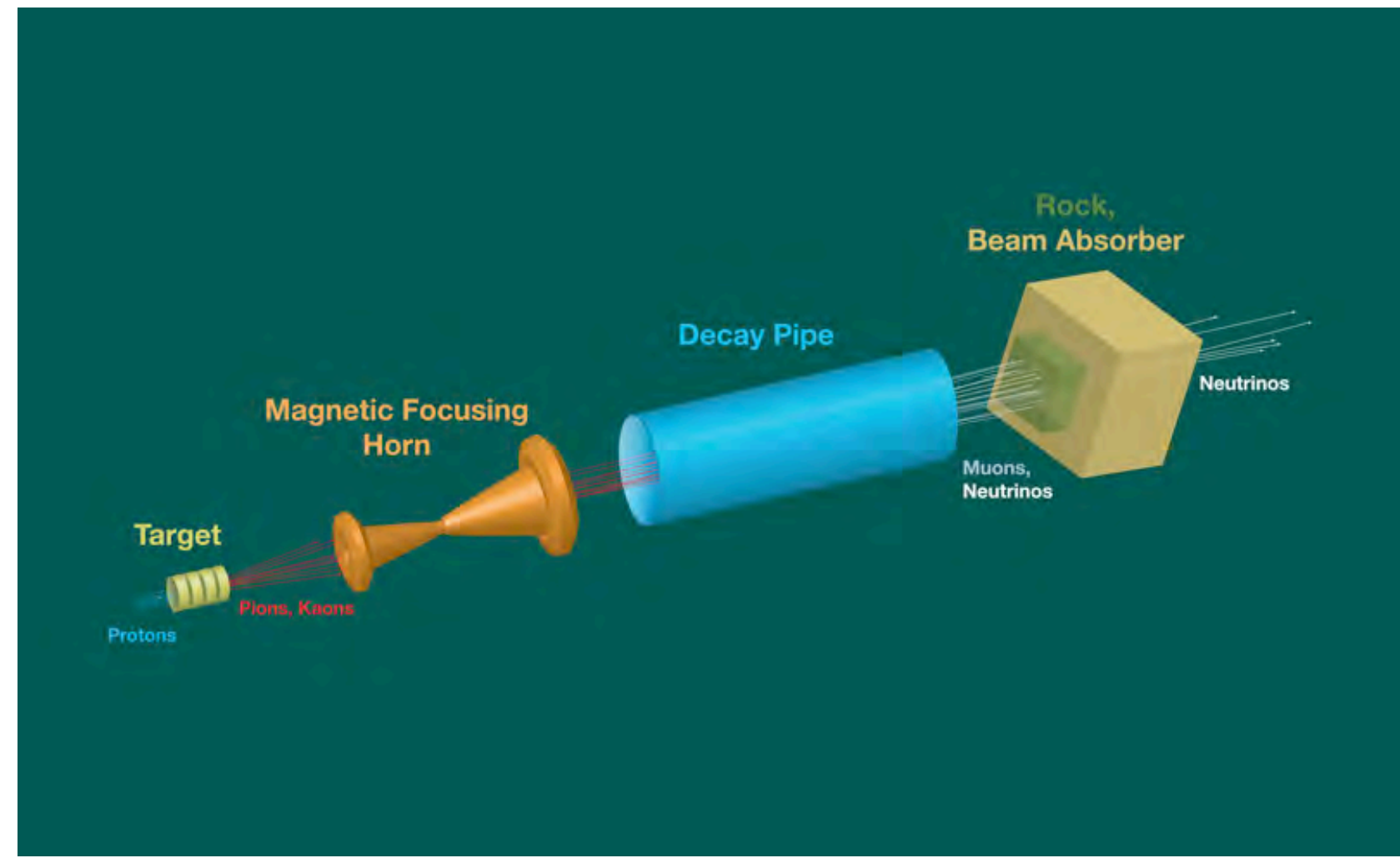




\section{Perché accelerare? E come?}

3. Le particelle elementari servono da sonde per il mondo microscopico sia attraverso la loro natura corpuscolare che ondulatoria

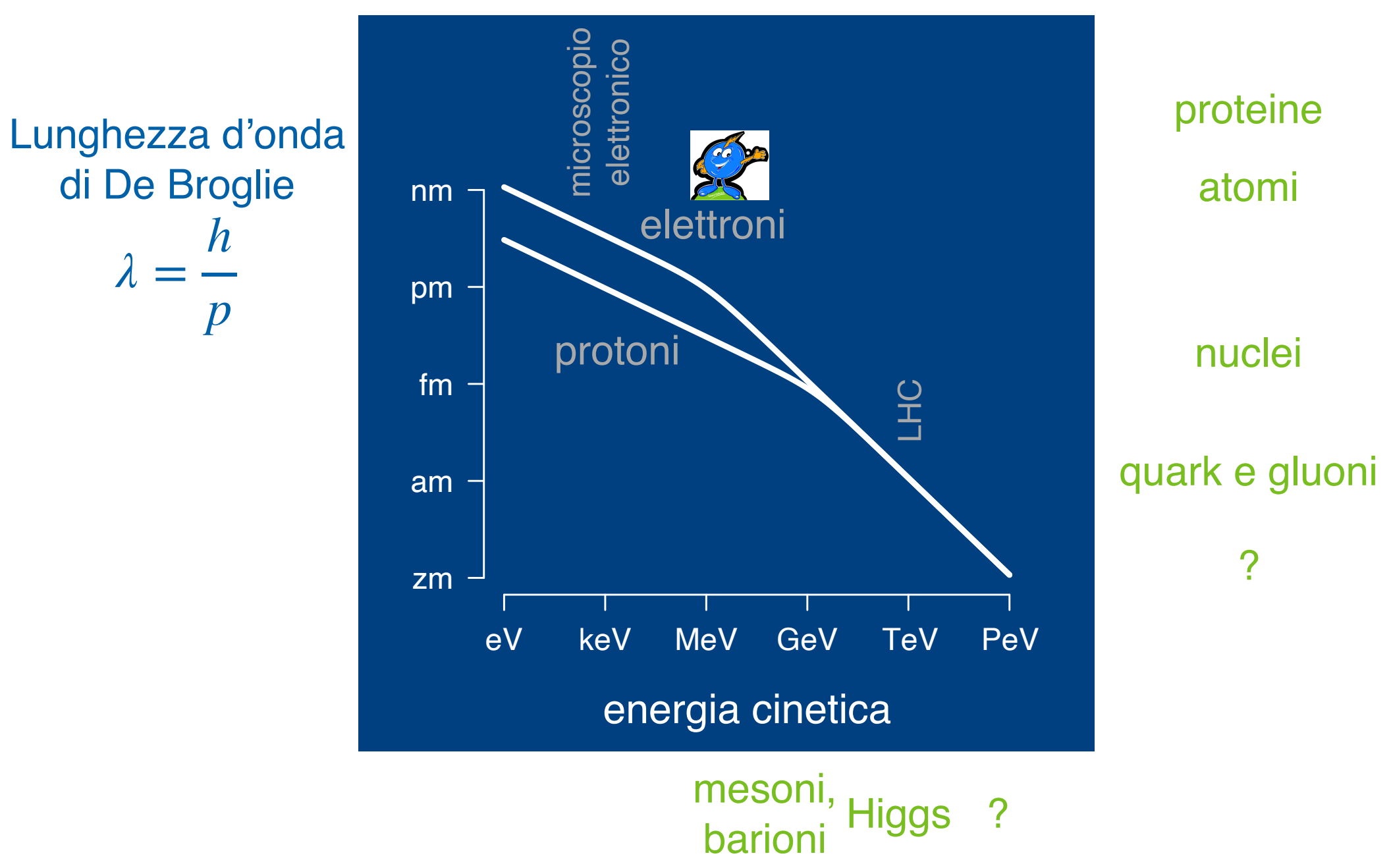




\section{Rutherford: il nucleo e il desiderio di sorgenti più intense}

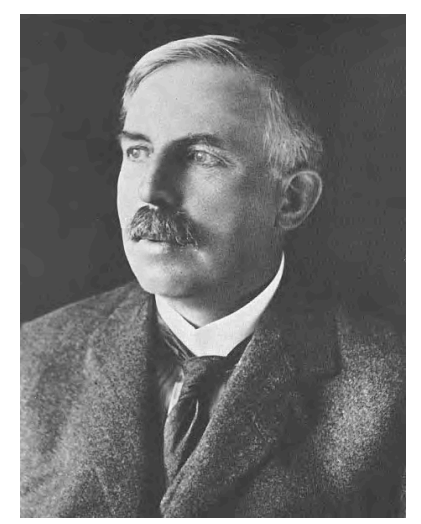

Particelle alfa da decadimento radioattivo su oro: scoperta del nucleo atomico

Particelle alfa su azoto gassoso:

trasmutazione (trasformazione in ossigeno)

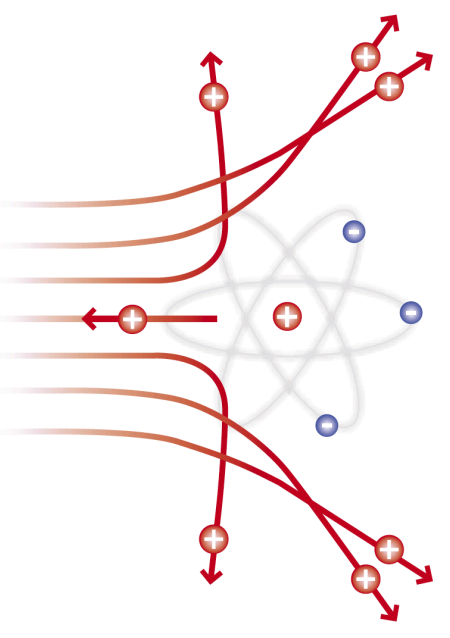

Necessità di sorgenti più energetiche e intense:

"It has long been my ambition to have available for study a copious supply of atoms and electrons which have an individual energy far transcending that of the a and $\beta$-particles from radioactive bodies. I am hopeful that I may yet have my wish fulfilled, but it is obvious that many experimental difficulties will have to be surmounted before this can be realised on a laboratory scale."

-Rutherford, Proc. Royal Society, 1927 


\section{Metodo diretto di accelerazione: produzione di alte tensioni}

Cockcroft e Walton al Cavendish Laboratory (1932) producono alte tensioni con trasformatore, condensatori e diodi (moltiplicatore di Greinacher)
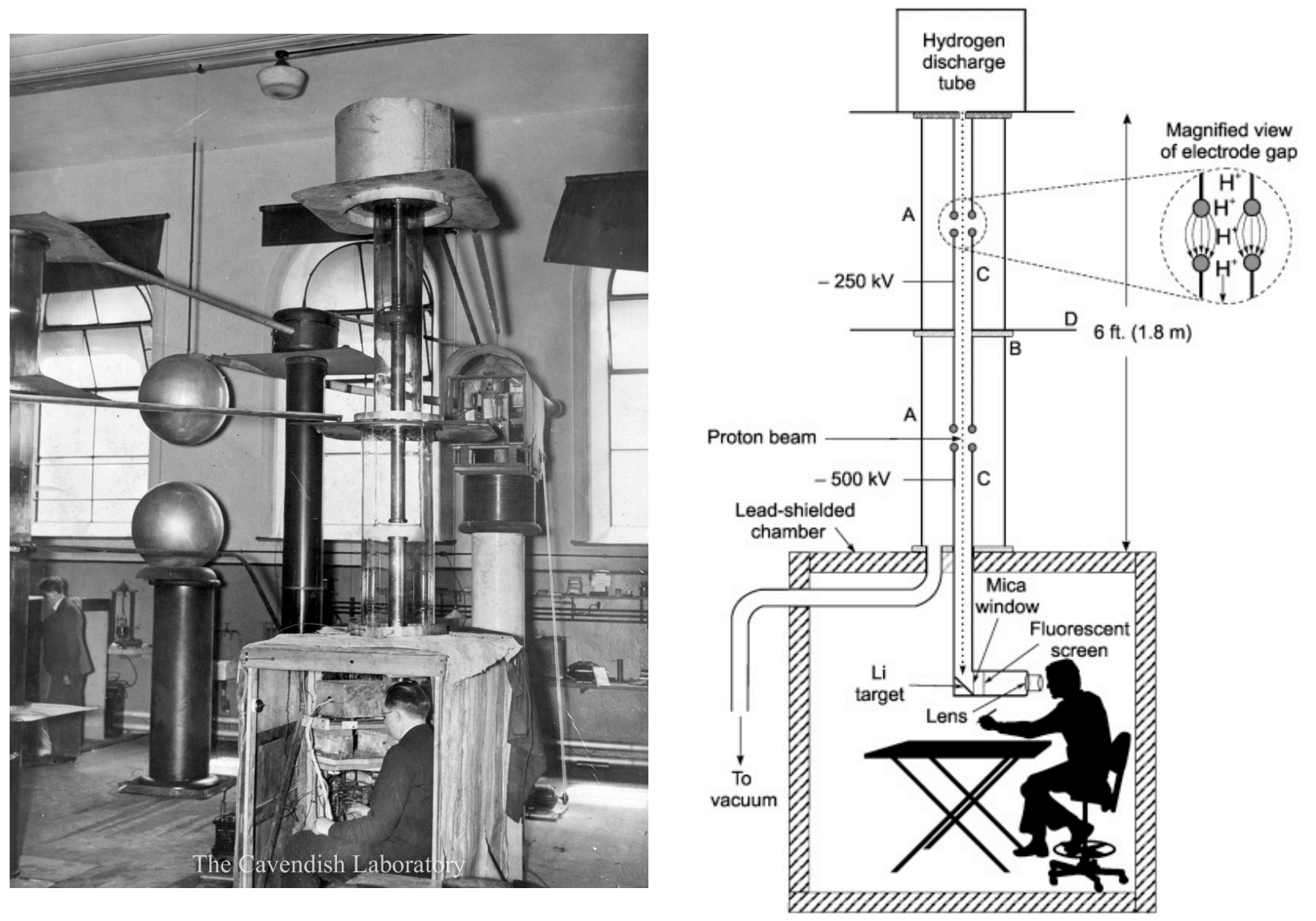

Protoni accelerati fino a 600 keV sono sufficienti per vincere la barriera coulombiana (repulsione nucleare)

Prima trasmutazione artificiale! Parte del bersaglio di litio viene trasformata in berillio 


\section{Metodo diretto di accelerazione: produzione di alte tensioni}

Il generatore di Van de Graaf (1929) converte il lavoro meccanico necessario a muovere una cinghia carica in potenziale elettrico

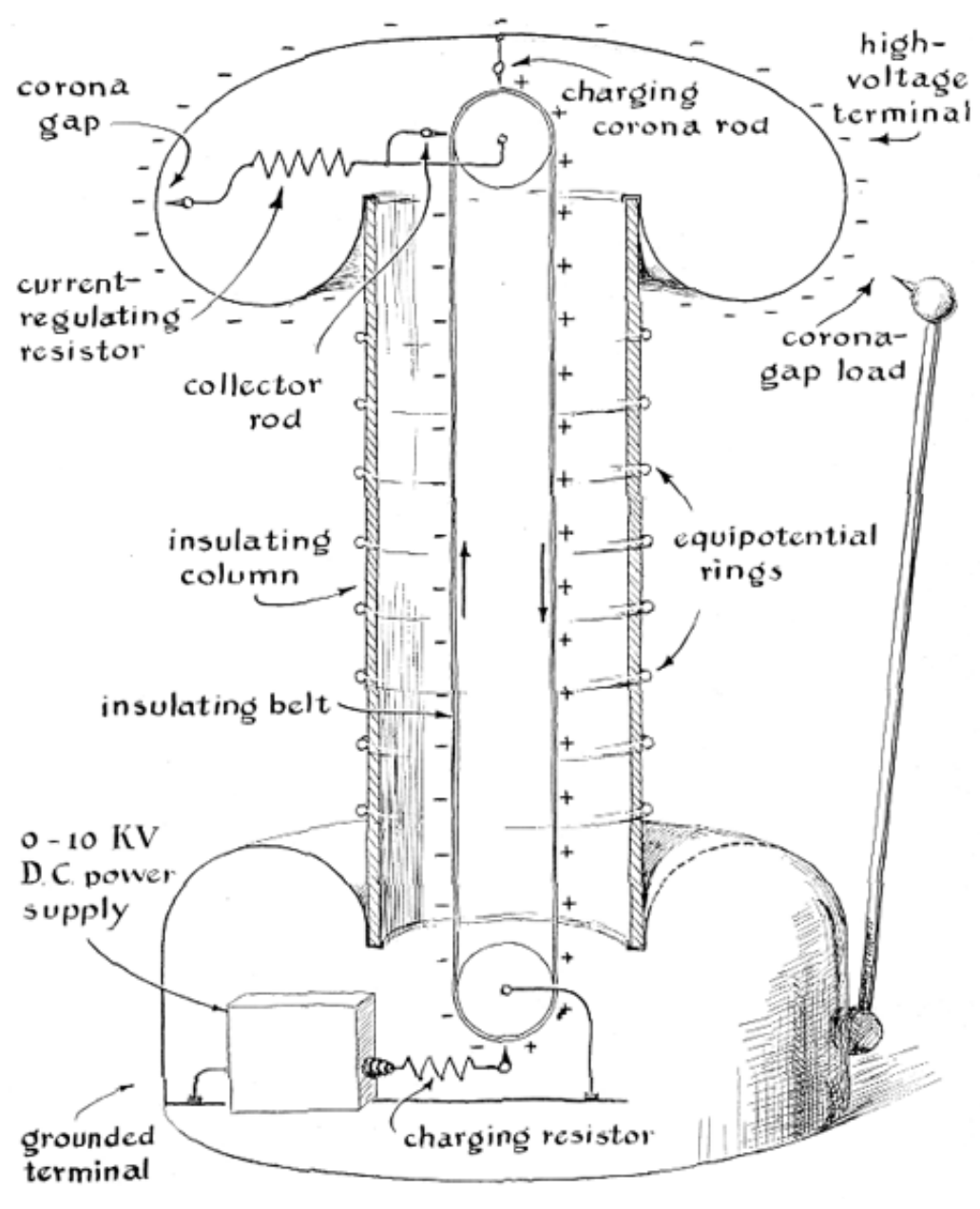

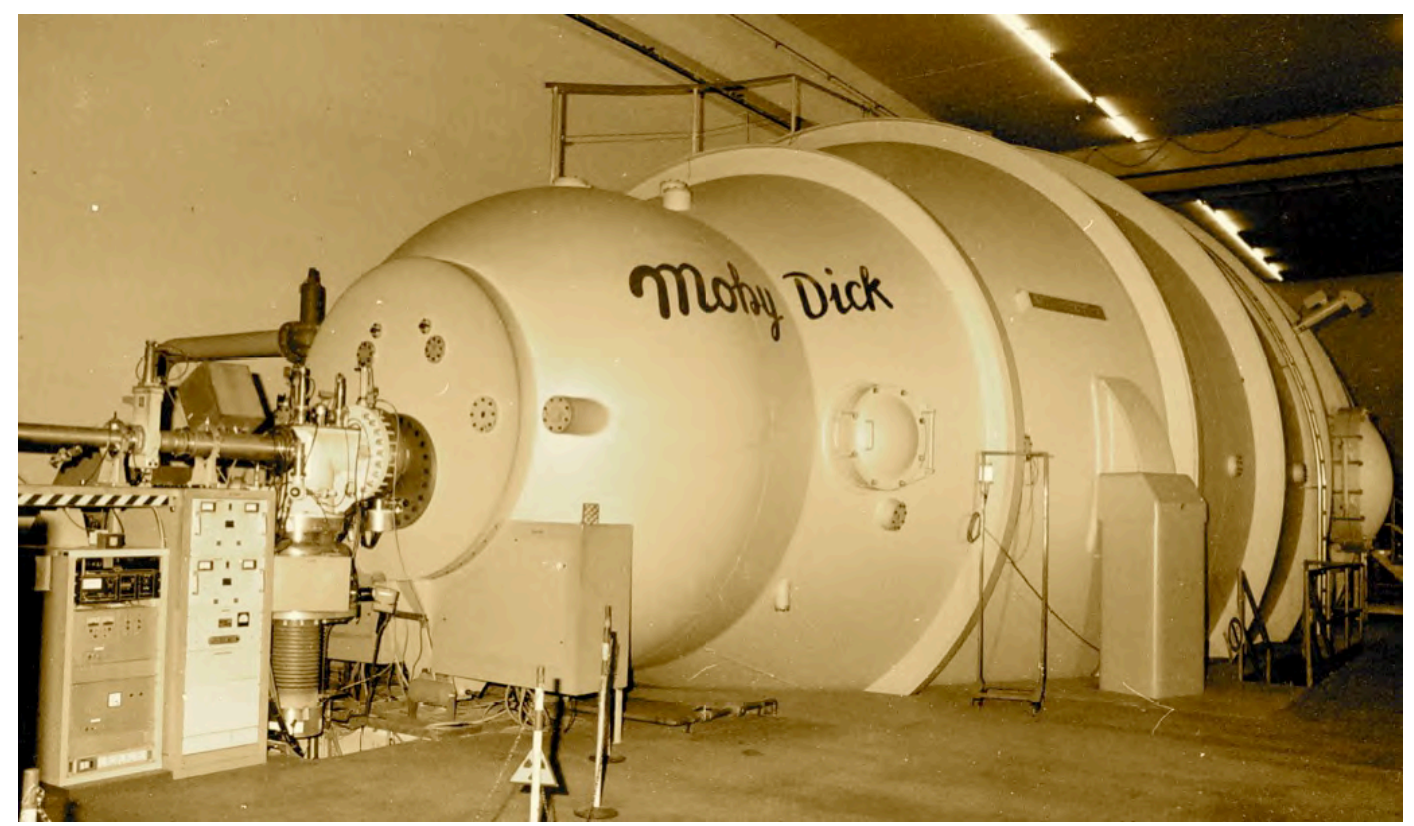

Tandem/XTU (15 MV) ai Laboratori Nazionali di Legnaro dell'INFN

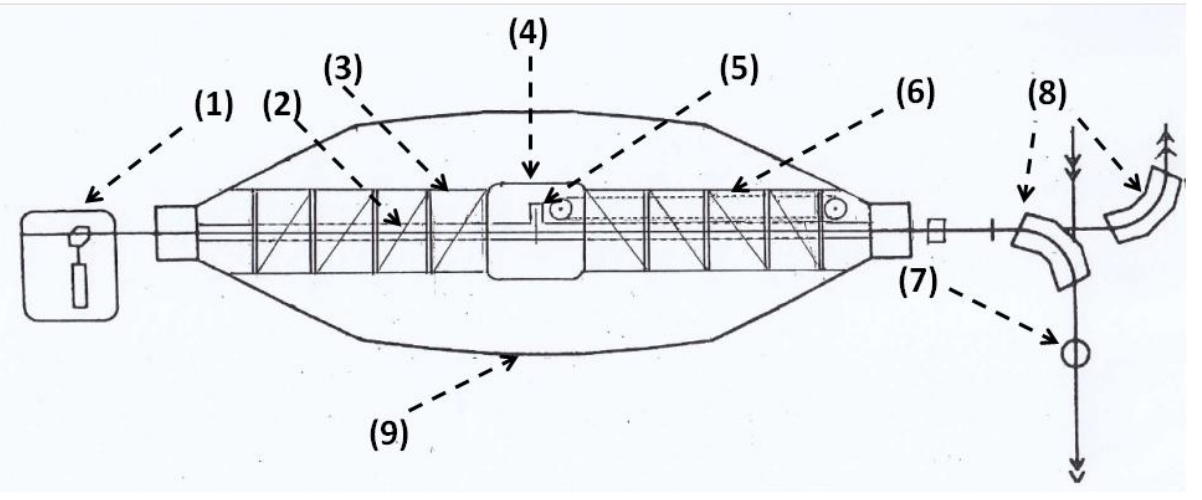




\section{Vantaggi e limiti delle macchine elettrostatiche}

- Energie fino a $\sim 100 \mathrm{MeV}$ adatte allo studio dei processi nucleari

- Stabilità della tensione importante per misure di sezioni d'urto in funzione dell'energia del fascio

- Intensità fino $\mathrm{a} \sim 0.1 \mathrm{~mA}$

- Possono raggiungere alcuni megavolt prima di produrre scariche

- Come andare oltre?

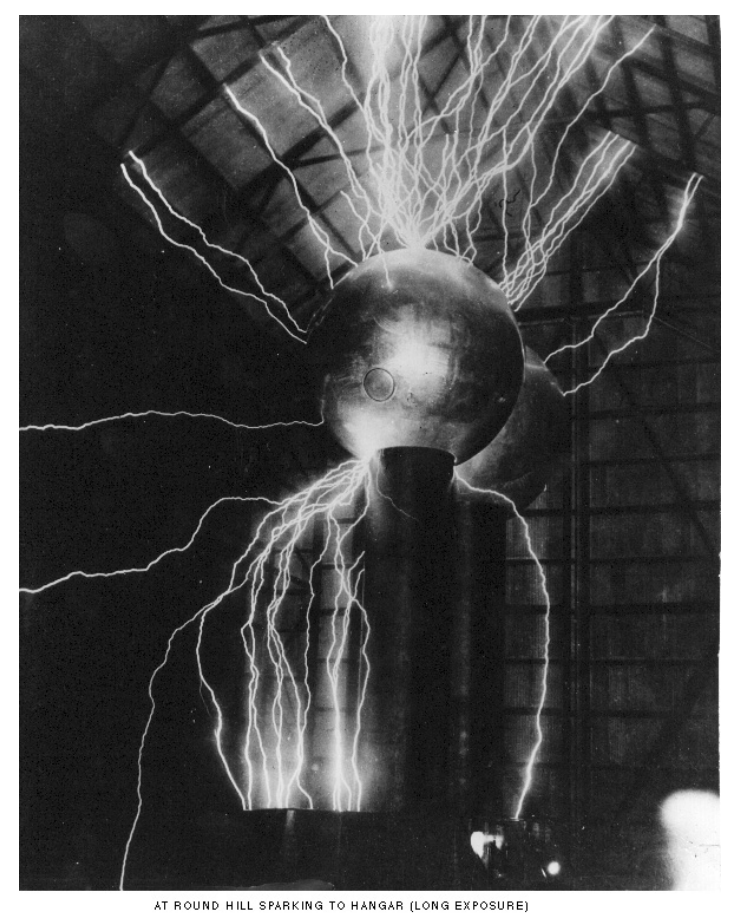




\section{Accelerazione multipla: il ciclotrone}

- Per evitare alte tensioni, diversi scienziati (Ising, Widerøe, Gabor, Szilard, Steenbeck) suggeriscono

1. Piccole accelerazioni, ripetute molte volte

2. Ricircolo del fascio di particelle

- Lawrence e Livingston costruiscono a Berkeley i primi ciclotroni (1930)
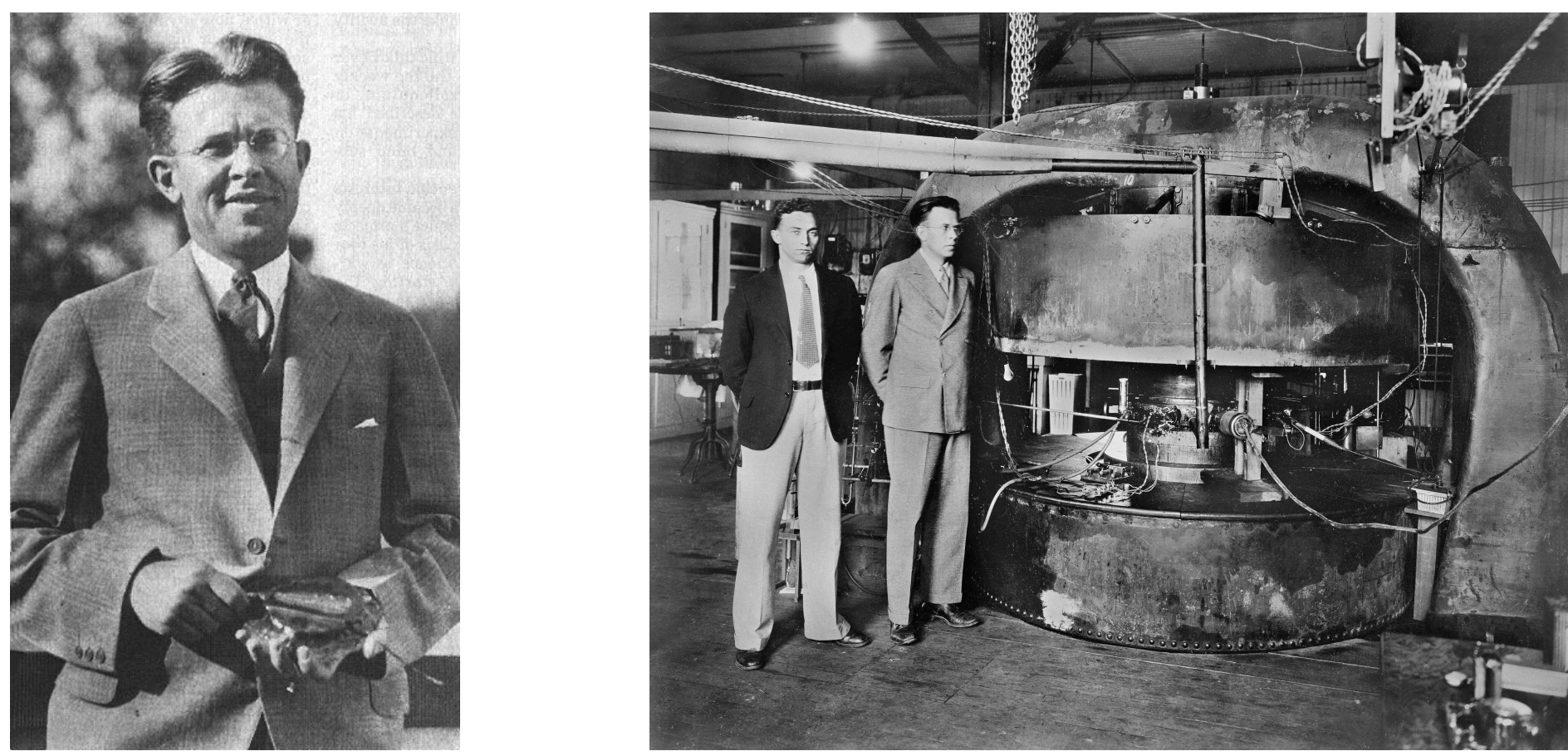


\section{Accelerazione multipla: il ciclotrone}

Campo magnetico confina

Campo elettrico alternato accelera le particelle

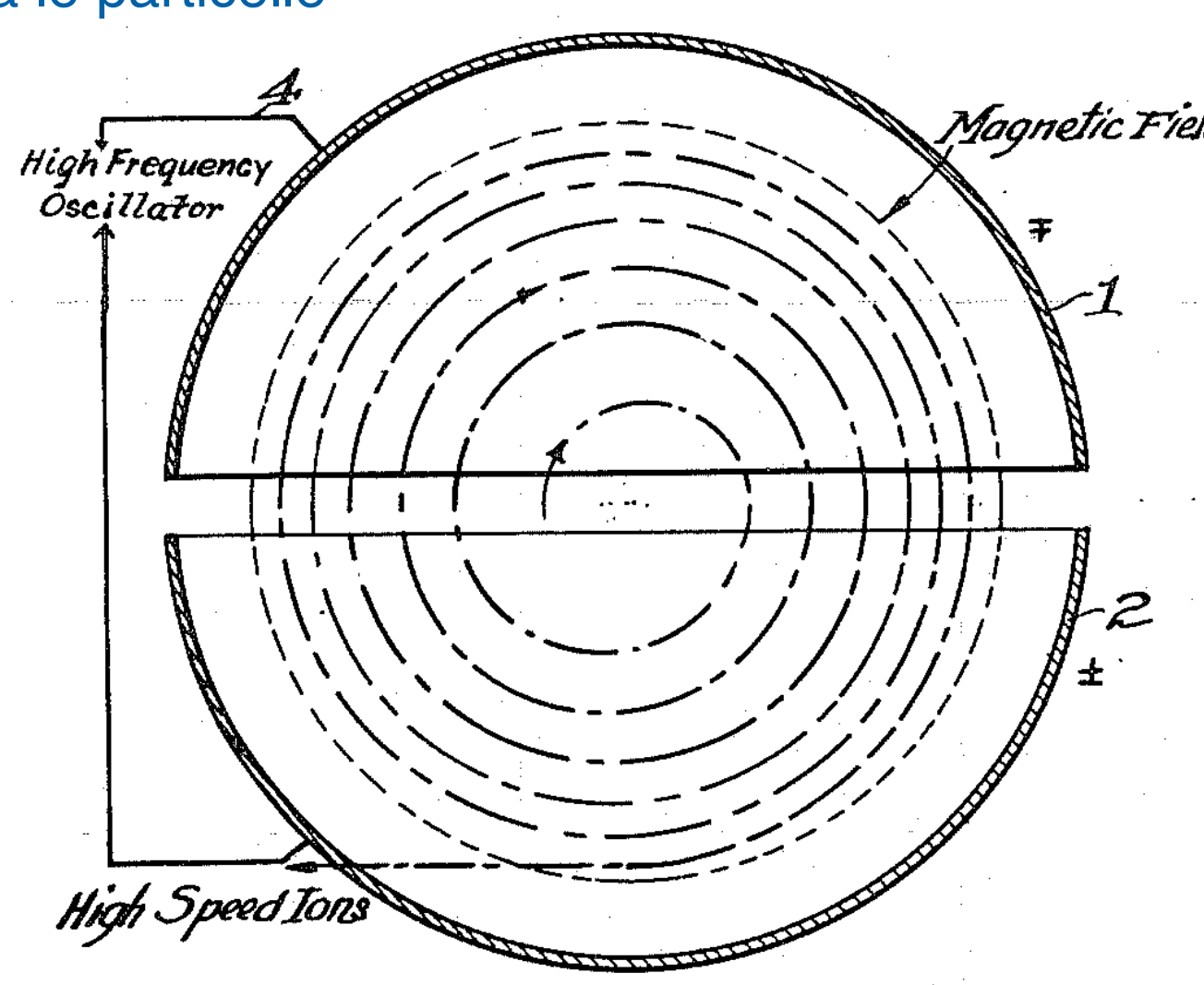

Focalizzazione "debole" tramite la curvatura delle linee di campo

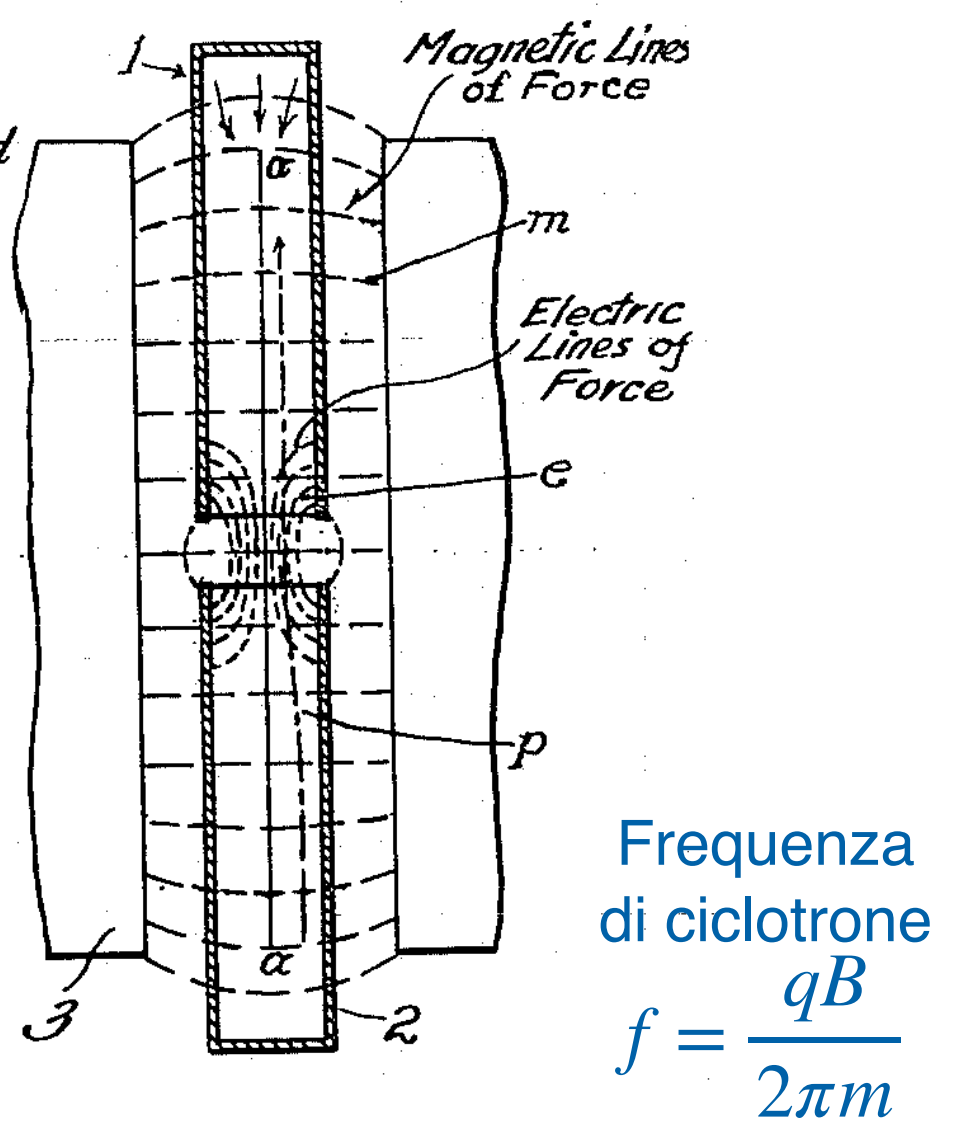

Principio chiave: la maggior lunghezza delle semi-circonferenze viene esattamente compensata dalla maggiore velocità - la frequenza di rivoluzione è indipendente dall'energia 
Nel 1948 a Berkeley, il ciclotrone da $4.7 \mathrm{~m}$ accelera particelle alfa fino a $380 \mathrm{MeV}$. Utilizzando bersagli di carbonio e berillio, vengono prodotti i primi mesoni artificiali, confermando le osservazioni sui raggi cosmici
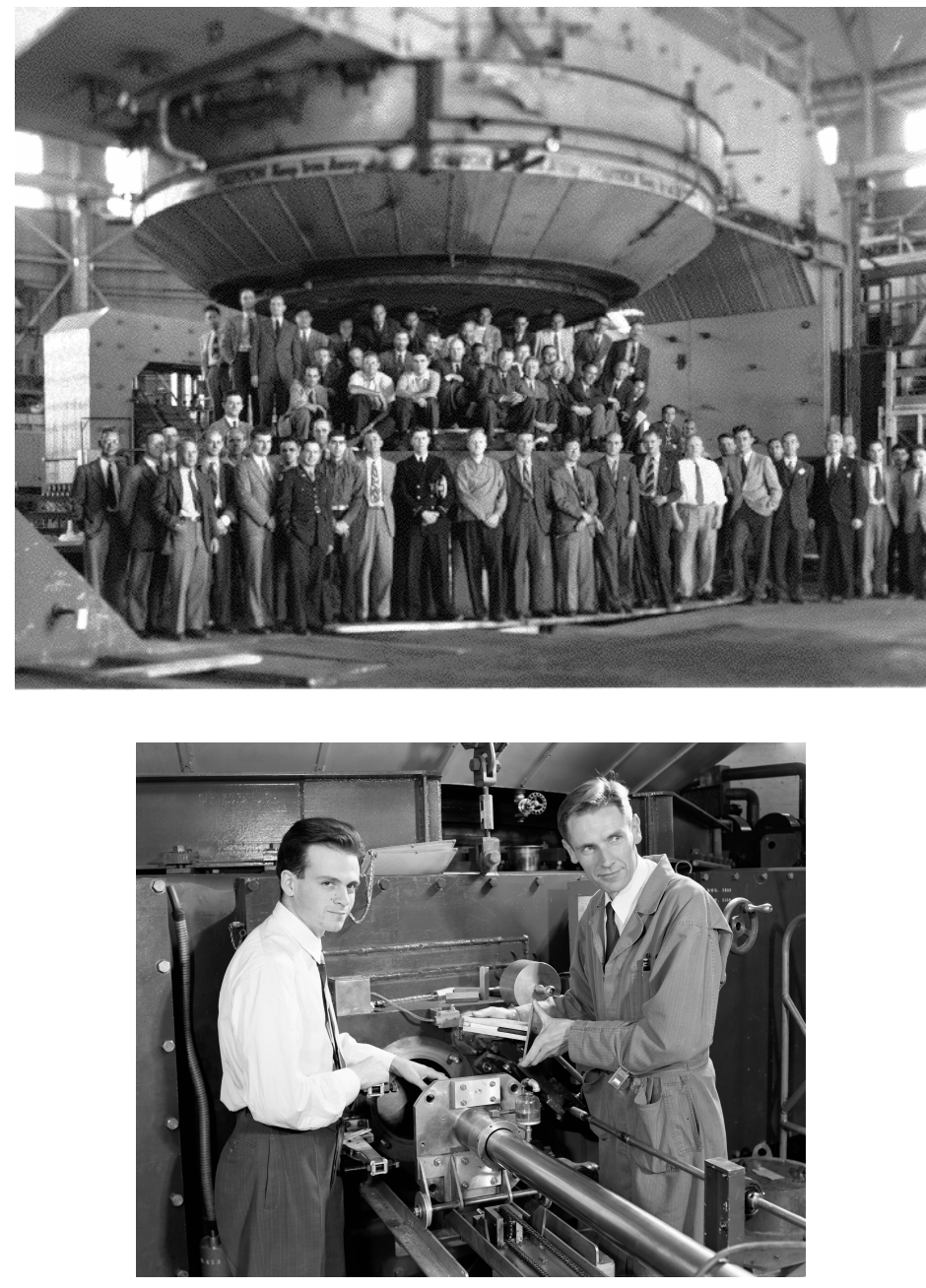

Lattes e Gardner
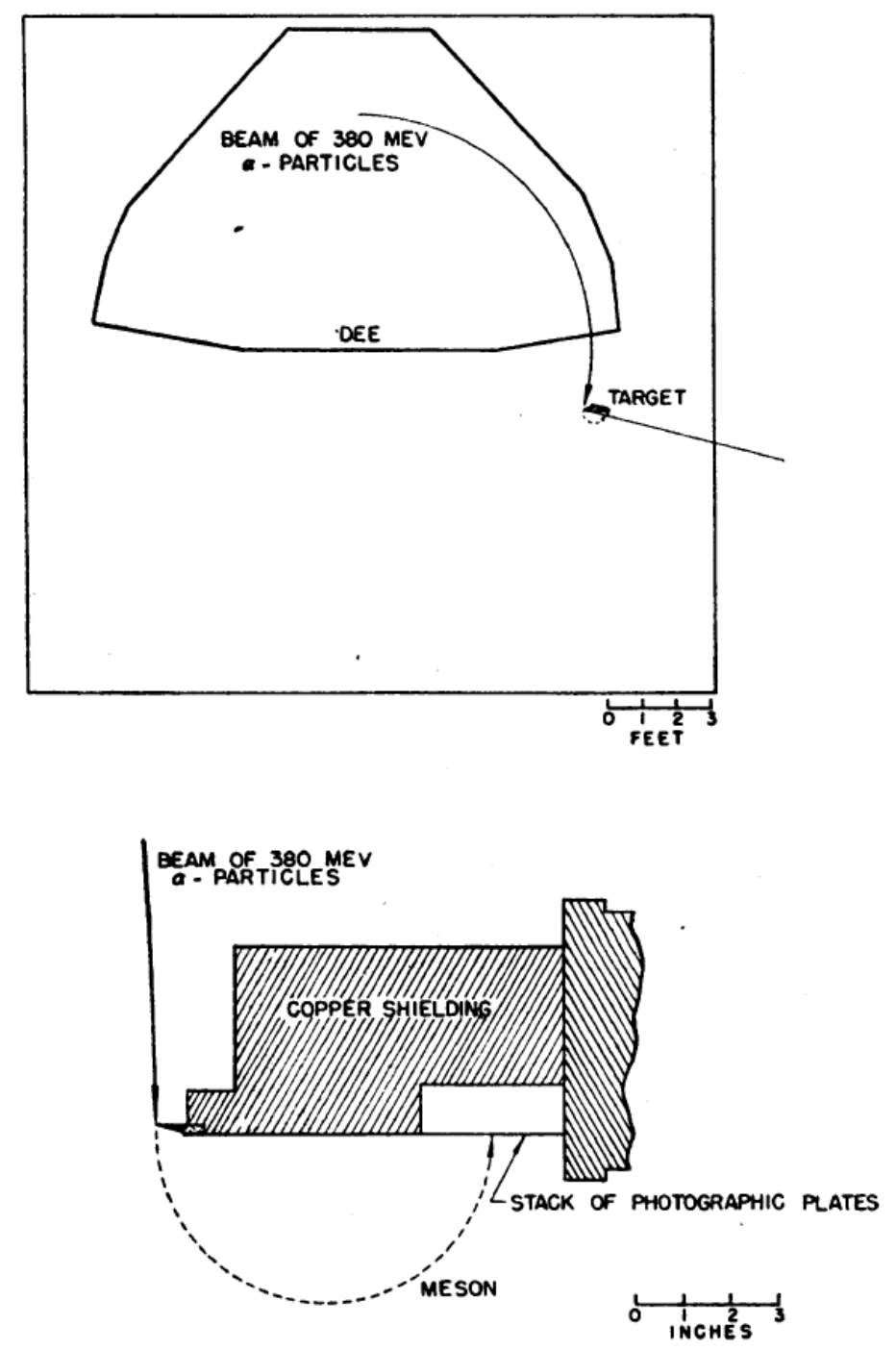

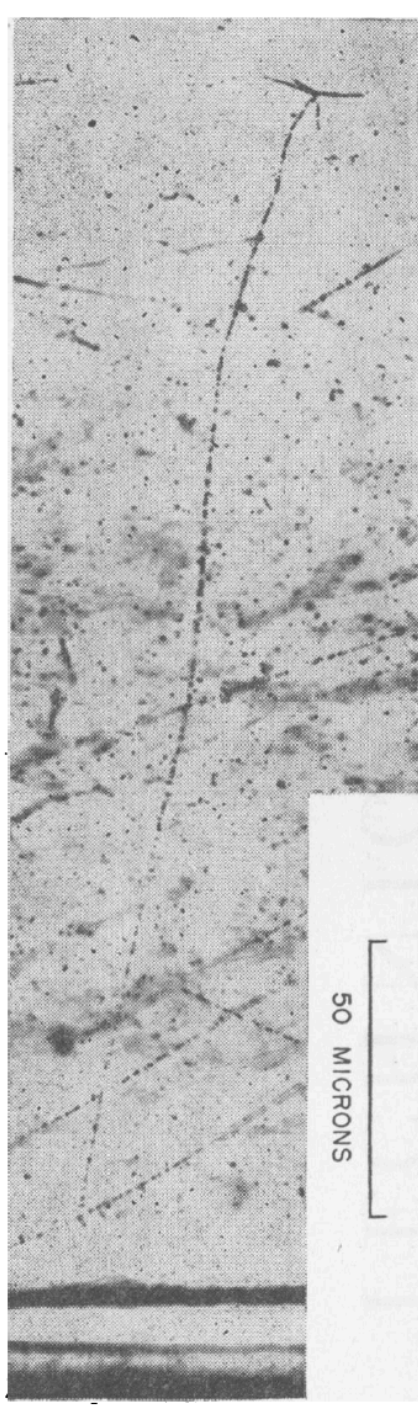




\section{Accelerazione multipla: l'acceleratore lineare (“linac”)}

Concetto introdotto da Ising (1924) e Widerøe (1928)

Accelerazioni multiple generate da campi elettrici alternati tra cilindri conduttori ("tubi di scorrimento"). Quando il campo è fuori fase, le particelle sono schermate.
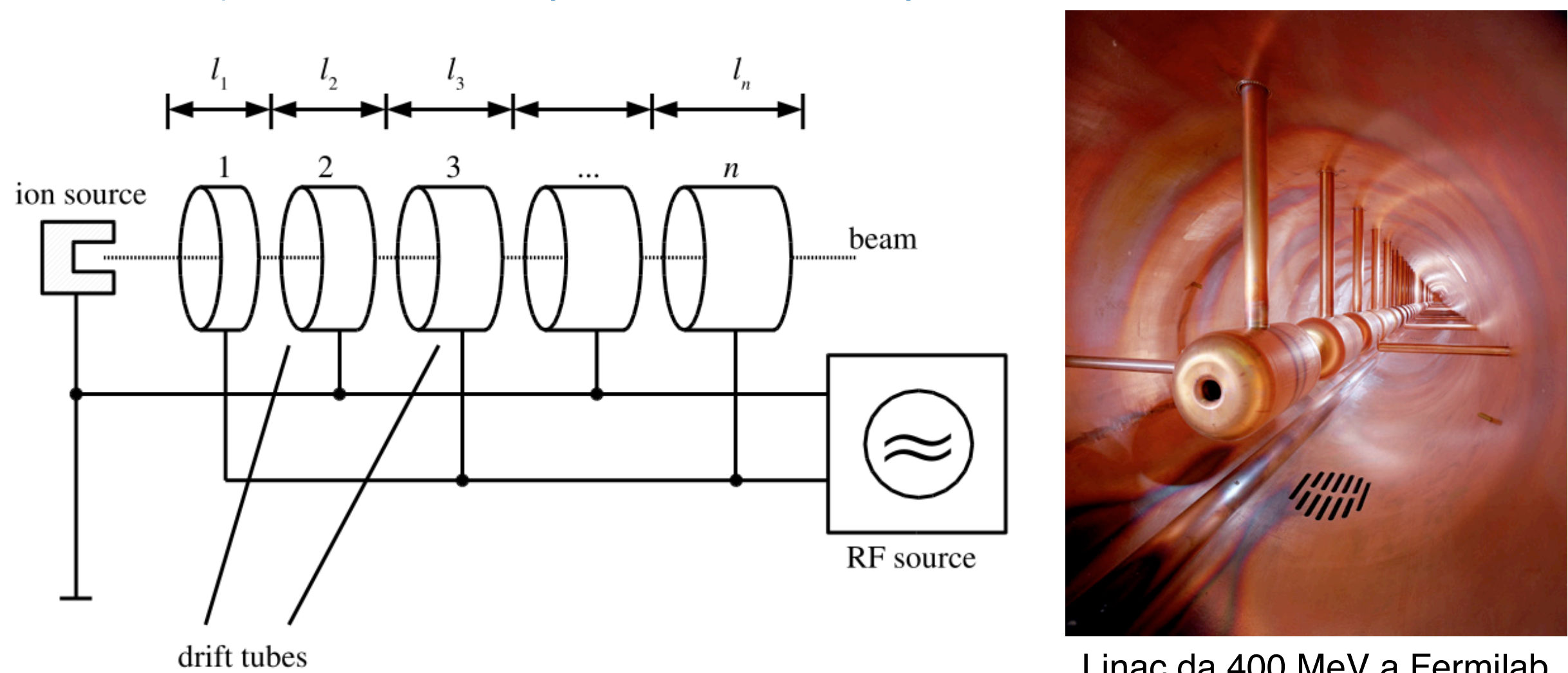

Linac da $400 \mathrm{MeV}$ a Fermilab

Prima macchina costruita nel 1931 da Sloan e Lawrence per ioni pesanti Lunghezza dei tubi e frequenza del campo aumentano con la velocità delle particelle Energia massima determinata dalla lunghezza totale della struttura 
L'acceleratore lineare di Stanford $(3 \mathrm{~km})$ permise lo studio della struttura dei nucleoni.

-1956, elettroni a $188 \mathrm{MeV}$ : misura delle dimensioni del protone, $\sim 0.7 \mathrm{fm}$

• 1969, elettroni a $17 \mathrm{GeV}$ : scoperta di "quark" all'interno del protone
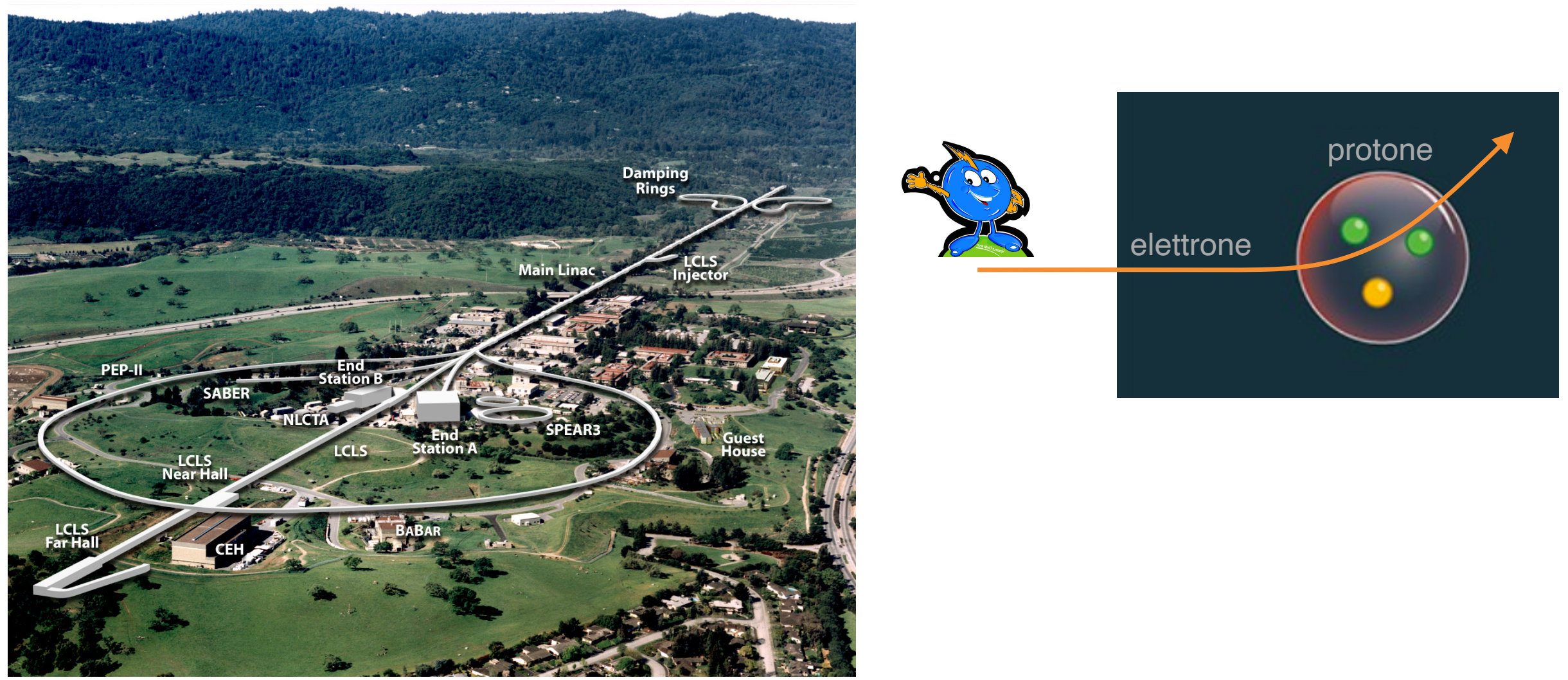


\section{Acceleratore ad induzione: il betatrone}

Si basa sul fenomeno dell'induzione elettromagnetica di Faraday

Il campo magnetico svolge tutte le funzioni principali:

- confina le particelle, con la sua componente verticale

- focalizza, tramite la curvatura delle linee di campo ai bordi (focalizzazione debole)

- accelera, attraverso il campo elettrico indotto dal campo magnetico variabile
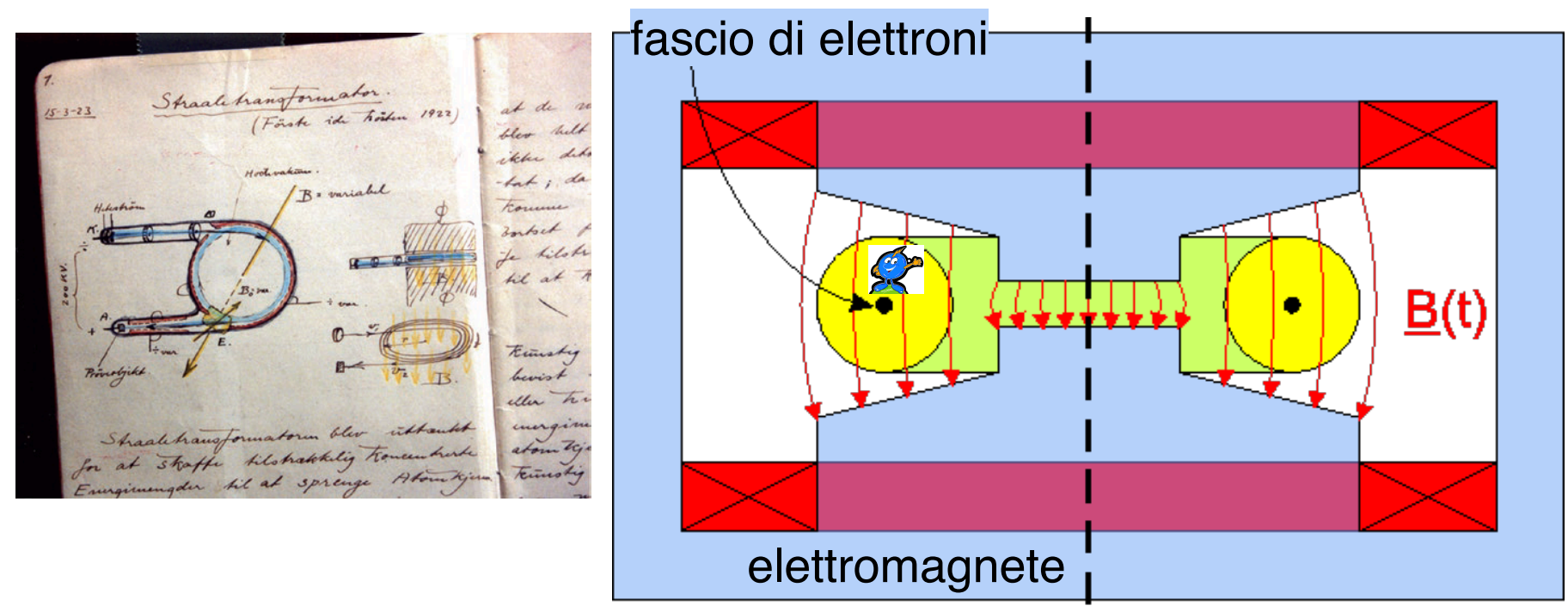

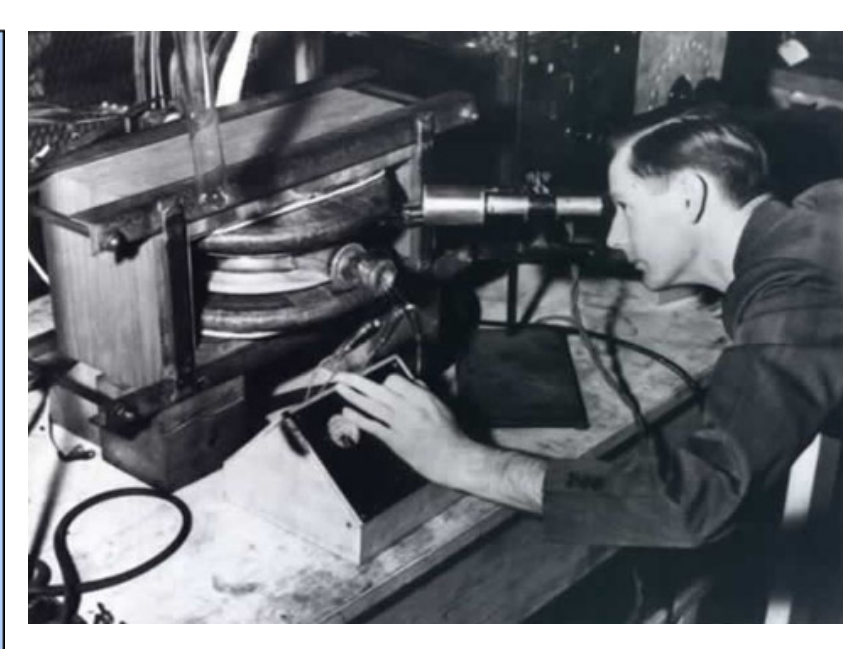

Primo betatrone: $2.3 \mathrm{MeV}, 1941$

Concepito da Widerøe (1923), sviluppato e costruito da Kerst (1940) Utilizzato raramente, ma importante per lo sviluppo della teoria delle orbite e della focalizzazione (Kerst e Serber, 1941) 
Stabilità di fase e sincrotroni: nascono i moderni acceleratori

- Per ciclotroni e betatroni

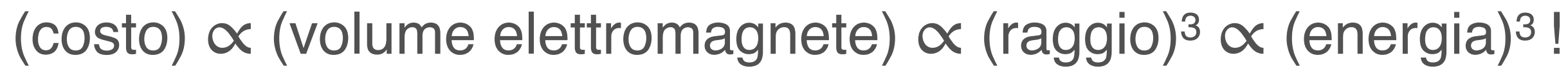
Una tendenza proibitiva...

- Oliphant (1943) sviluppa il concetto di sincrotrone. Veksler e McMillan (1945) scoprono indipendentemente la stabilità di fase. Incrementando insieme frequenza di accelerazione e campo magnetico, le particelle "seguono" i campi e possono rimanere su un'orbita costante al crescere dell'energia.

- La parte centrale dell'elettromagnete è superflua. La macchina assume la forma di anello.

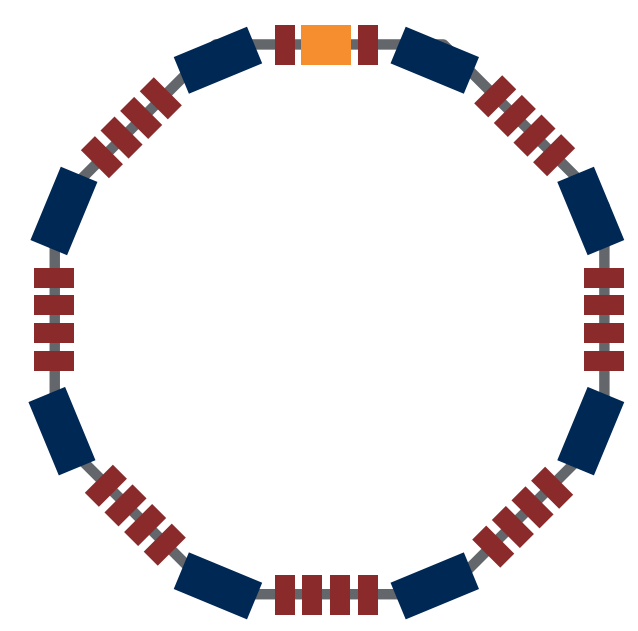




\section{I primi sincrotroni}

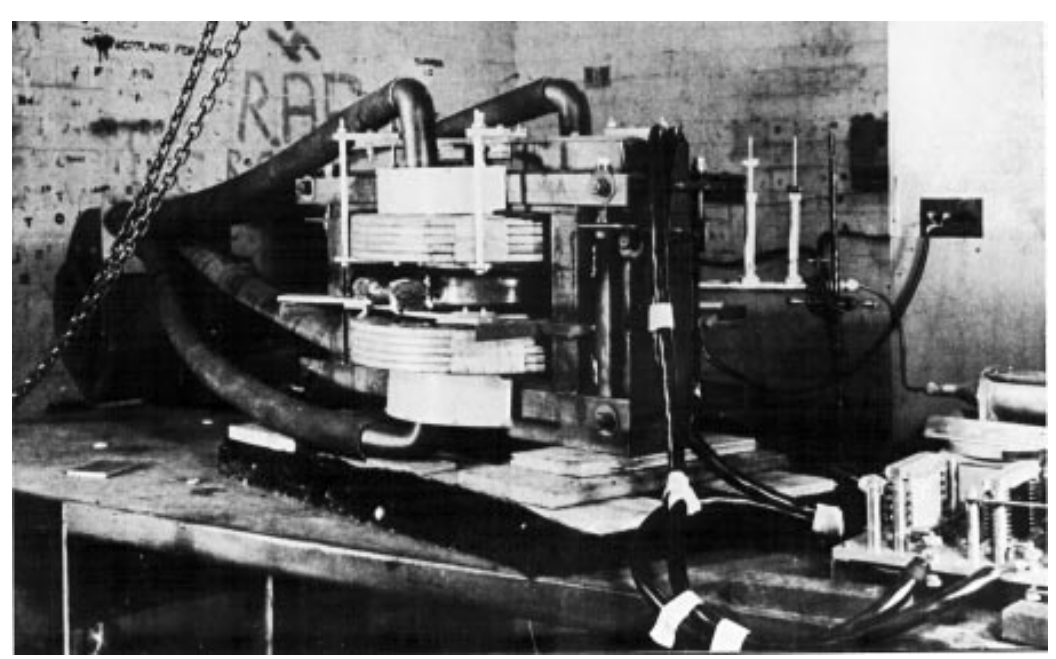

Primo sincrotrone: F. Goward, UK (1946) (betatrone modificato)

Sincrotrone da $300 \mathrm{MeV}$ della General Electric (1946)

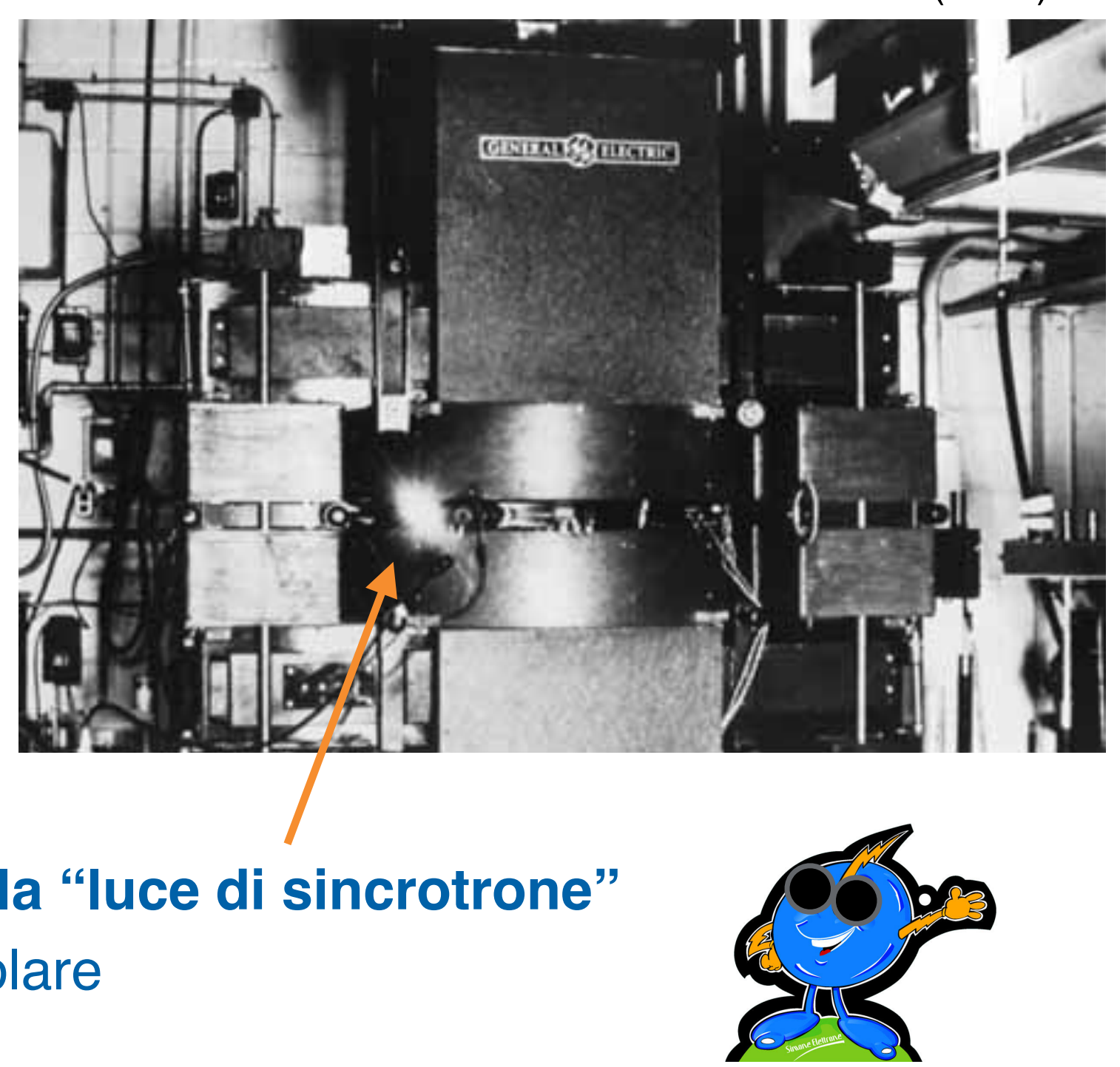


II Bevatron a Berkeley genera protoni fino a $6 \mathrm{GeV}$, energia sufficiente a produrre e scoprire gli antiprotoni (1955)

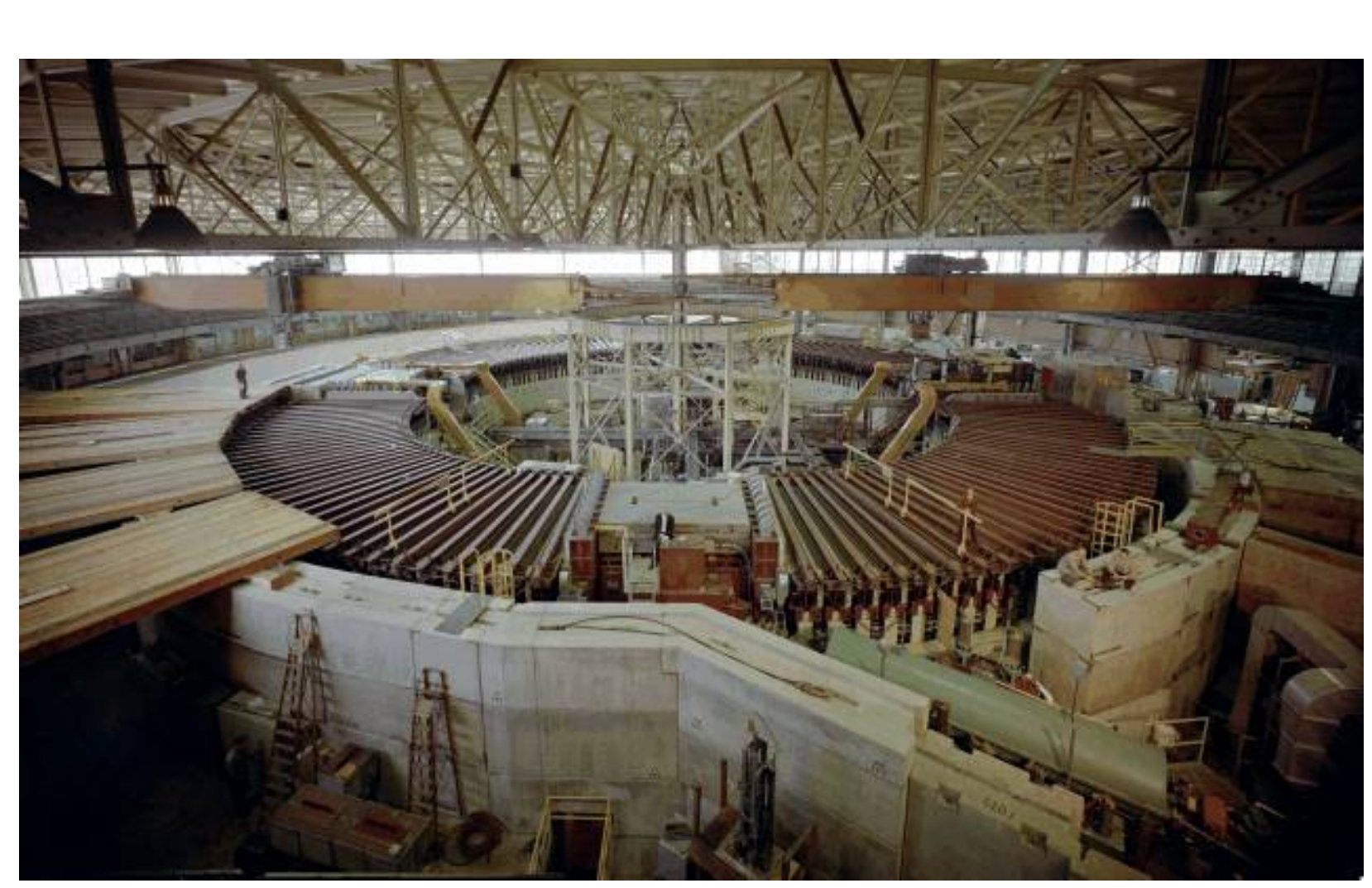

FASCIO DI PROTONI

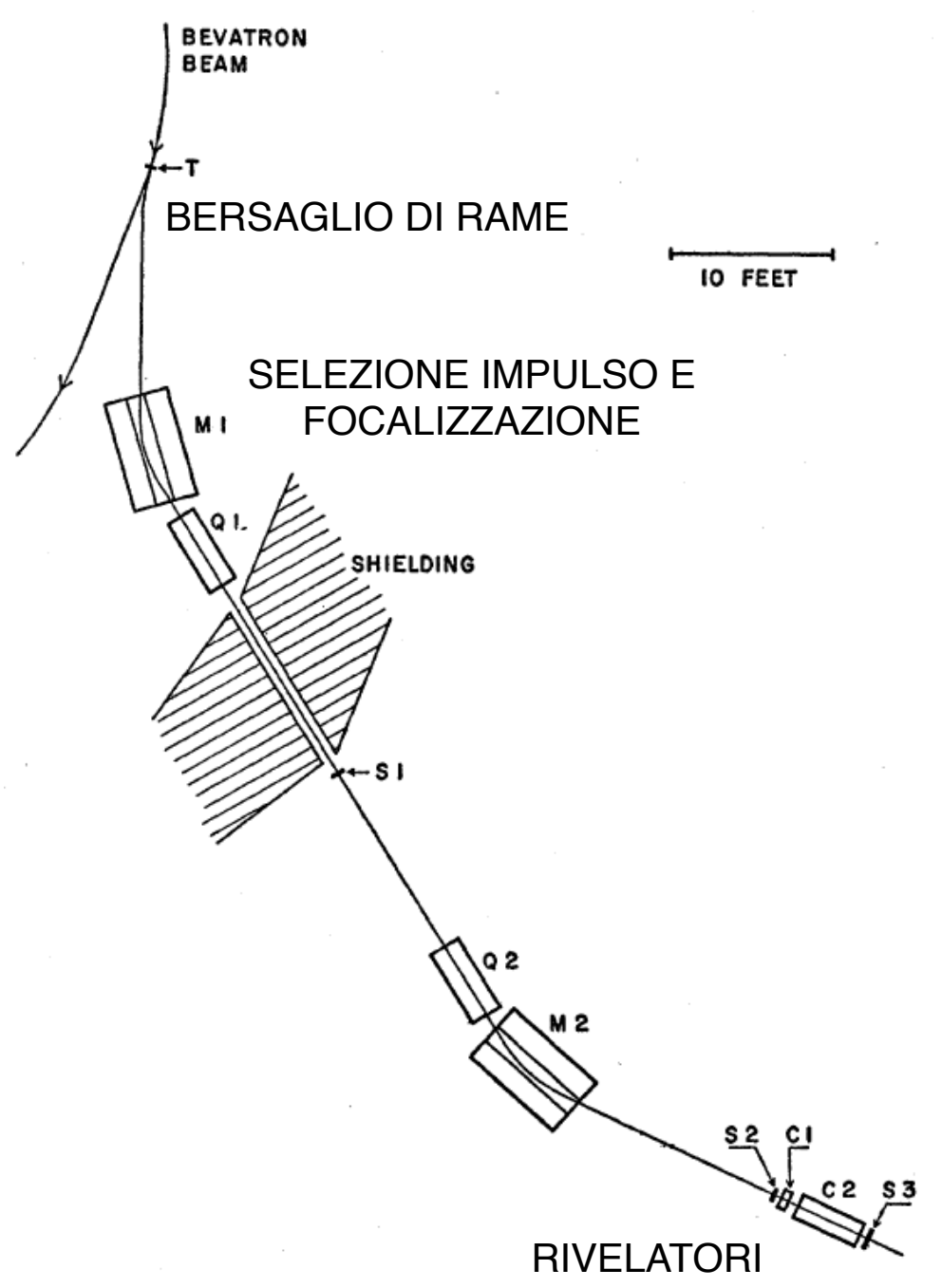




\section{Gradiente alternato e focalizzazione forte}

In analogia con l'ottica, Christofilos (1950) e Courant, Livingston e Snyder (1952) scoprono che si ottiene una focalizzazione più compatta ed efficiente aumentando il gradiente del campo magnetico e alternandone il segno (lenti focalizzanti e defocalizzanti)

focalizzazione debole (ciclotroni, betatroni, primi sincrotroni)

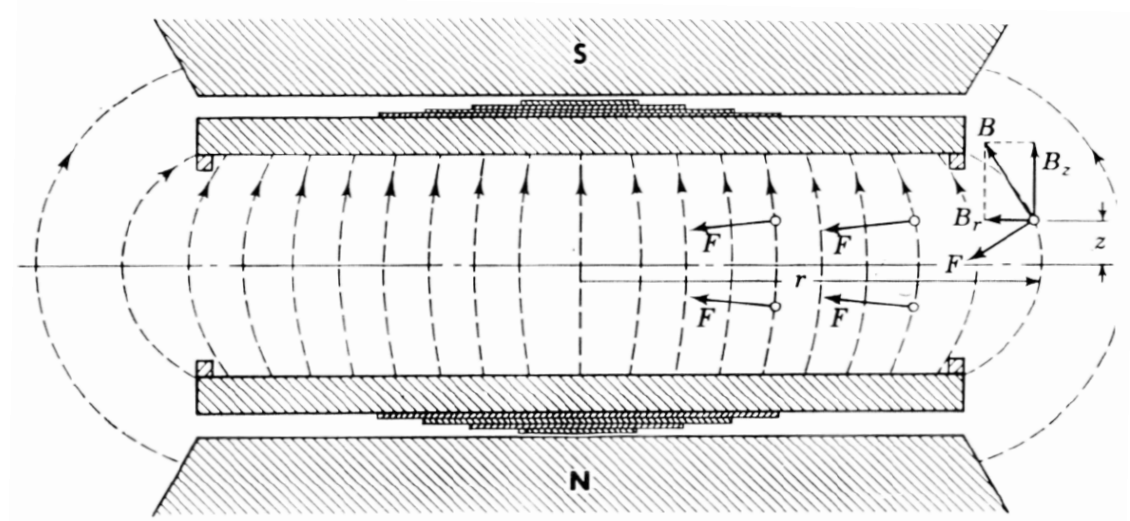

grandi escursioni di orbita e necessità di avere grandi camere evacuate e magneti voluminosi focalizzazione forte e gradiente alternato

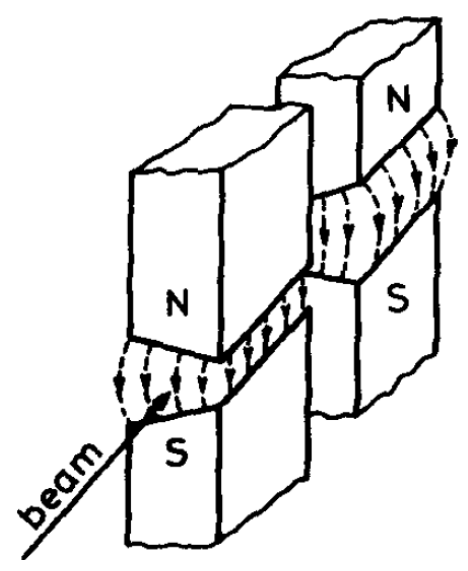

fasci, magneti e camere da vuoto molto più compatti 


\section{Modello semplificato di sincrotrone moderno}

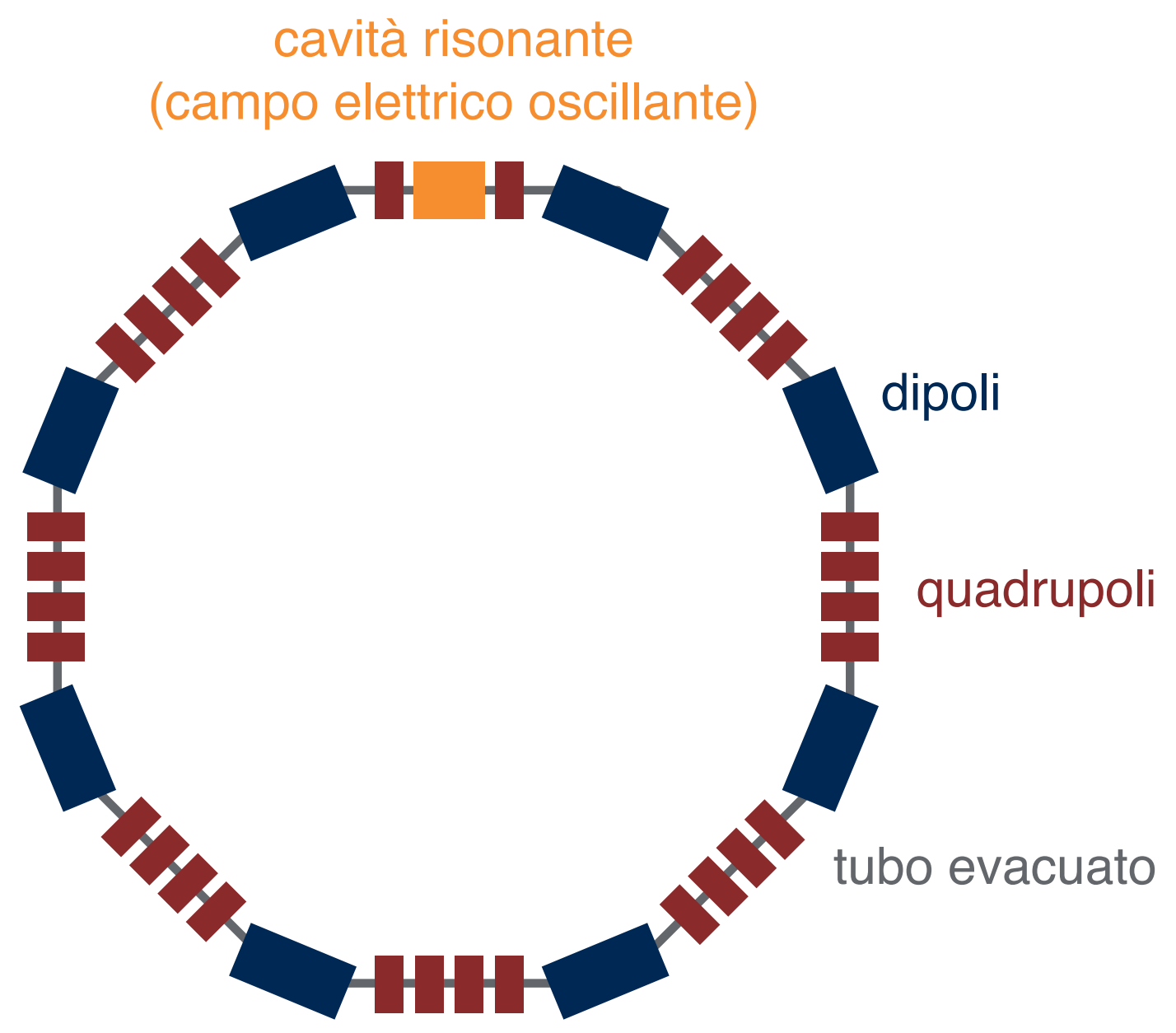

Separazione tra le funzioni di deflessione (magneti dipolari) e focalizzazione (magneti quadrupolari) 


\section{Anelli di collisione a fasci incrociati}

- Negli esperimenti a bersaglio fisso, gran parte dell'energia viene "sprecata" sotto forma di energia cinetica dei prodotti (conservazione dell'energia e dell'impulso)

- L'energia disponibile per creare nuove particelle (energia nel centro di massa) è proporzionale alla radice dell'energia dei proiettili: $E_{\mathrm{cm}}=\sqrt{m_{A}^{2}+m_{B}^{2}+2 E_{A} m_{B}}$

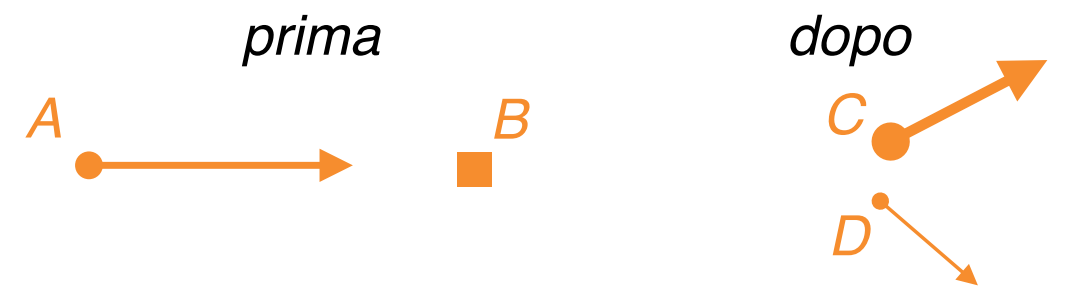

- In collisioni frontali $\left(\mathbf{p}_{A}=-\mathbf{p}_{B}\right)$, tutta l'energia è disponibile: $E_{\mathrm{cm}}=E_{A}+E_{B}$

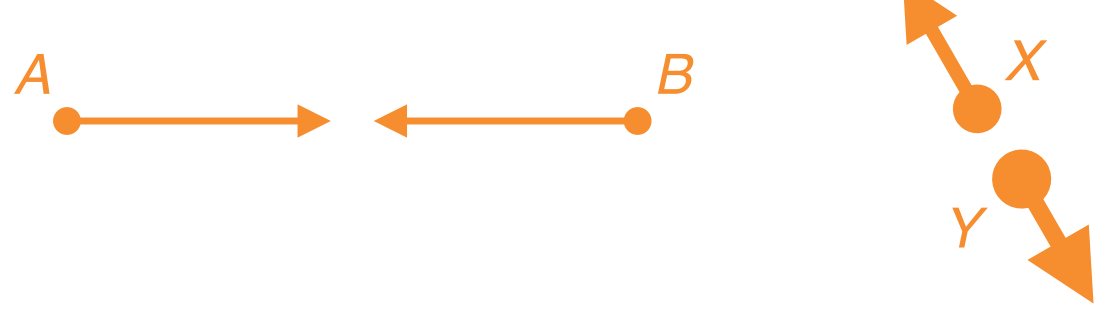

Ricordare:

$$
\Delta N=\epsilon \cdot \sigma \cdot v \cdot n_{A} \cdot n_{B} \cdot \Delta V \cdot \Delta t
$$

- Limiti degli anelli di collisione

- densità dei fasci molto minore della densità di bersagli solidi, liquidi o gassosi

- la densità di carica (fasci non neutri) crea forti repulsioni coulombiane 


\section{I primi anelli di collisione}

"Idea folle": materia e antimateria (stessa massa, carica opposta) circolanti nello stesso tubo per studiare i prodotti di annichilazione (Widerøe, Touschek)

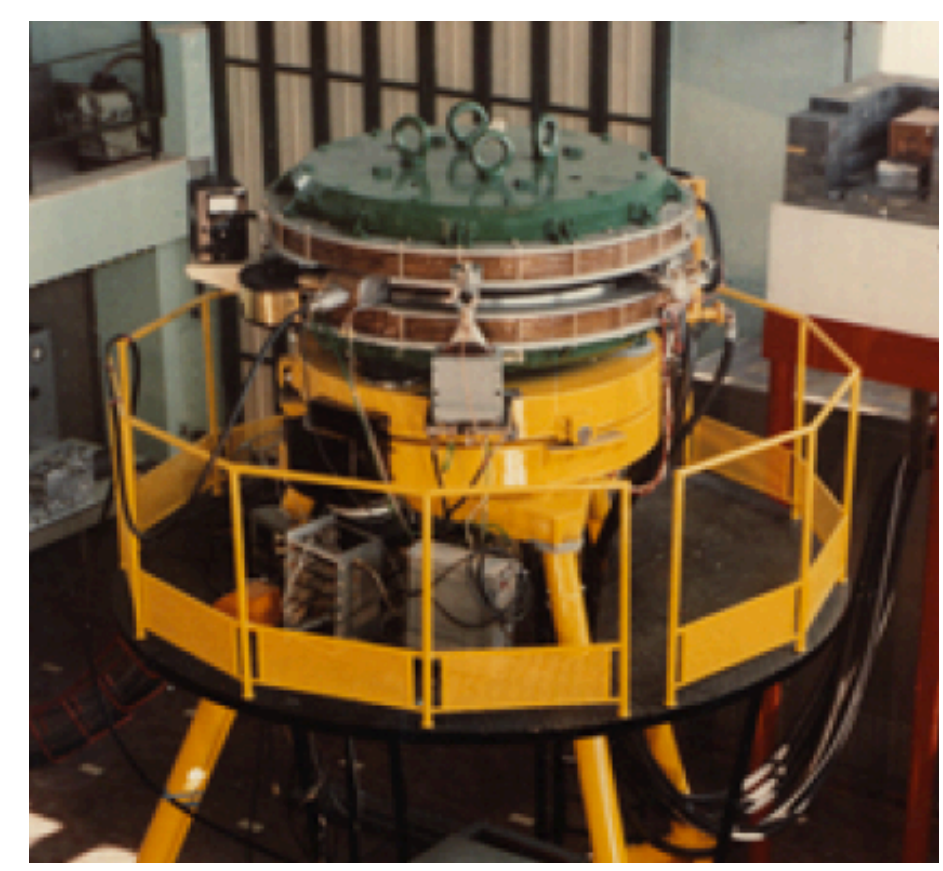

AdA (Anello di Accumulazione)
Approcci alternativi con collisioni elettrone-elettrone:

- macchina di Stanford-Princeton - VEP1 a Novosibirsk

\section{Prime collisioni elettrone-positrone}

$250 \mathrm{MeV}, 1.3 \mathrm{~m}$ di diametro

Frascati (1961) e Orsay (1964) 


\section{La scoperta del quark "charm" e del "charmonio": la $J / \psi$}

Nel novembre 1974, due gruppi annunciano simultaneamente l'osservazione di un'inattesa risonanza a $3.1 \mathrm{GeV}$, ossia un numero di eventi molto più grande del previsto

\section{Alternating Gradient Synchrotron a Brookhaven} protoni su bersaglio fisso
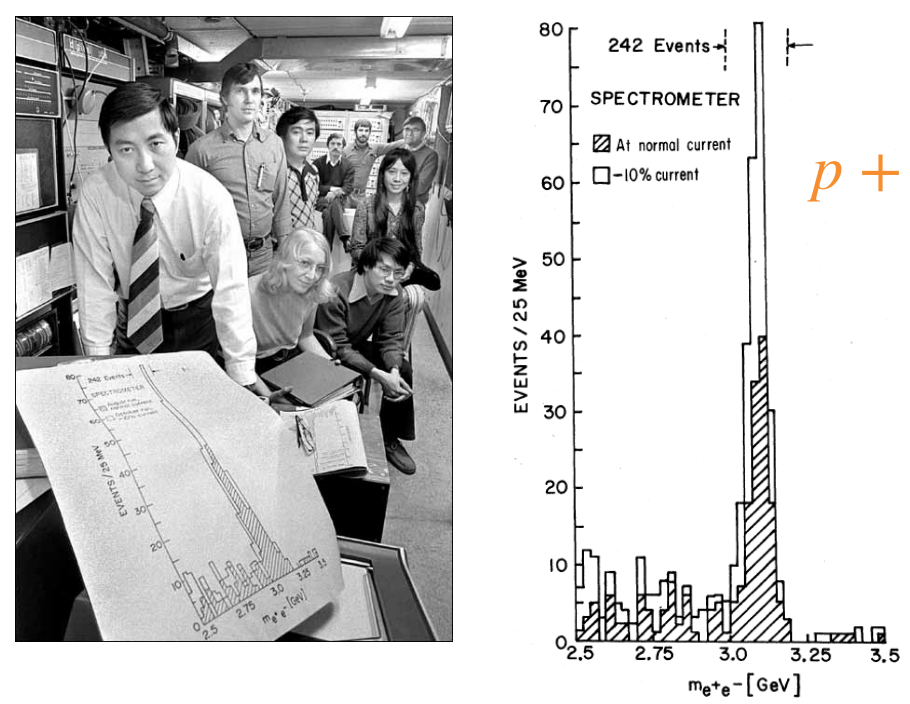

\section{SPEAR a Stanford} collisioni elettrone-positrone

Confermata dopo poche ore (!) in ADONE a Frascati

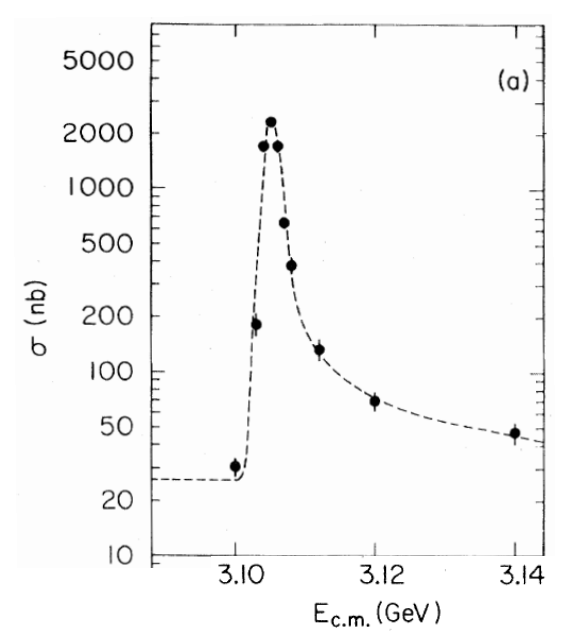

- Esistono quark che pesano più dei protoni!

- Il charmonio, stato legato di due quark pesanti $(c \bar{c})$, permise di studiare le forze nucleari in un sistema semplice (non relativistico)

- Soprannominato l' "atomo di idrogeno delle interazioni forti", in analogia con il ruolo dell'atomo di idrogeno in meccanica quantistica 


\section{Cenni sugli sviluppi recenti}

- Innumerevoli scoperte sono state rese possibili dalle macchine acceleratrici - L'avvento della superconduttività applicata a magneti e cavità risonanti ha aperto orizzonti prima impensabili
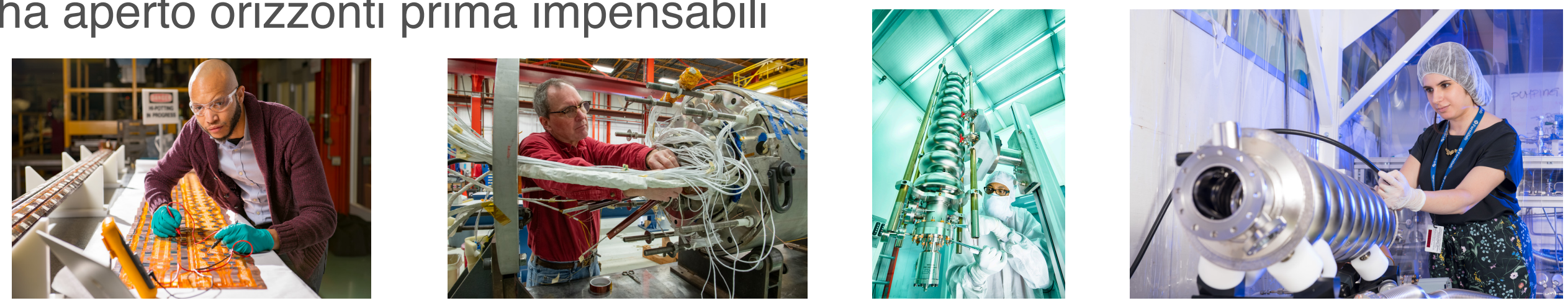

- Gli anelli di collisione (Tevatron a Fermilab, LEP e LHC al CERN, etc.) sono tra gli strumenti scientifici più potenti e complessi mai costruiti

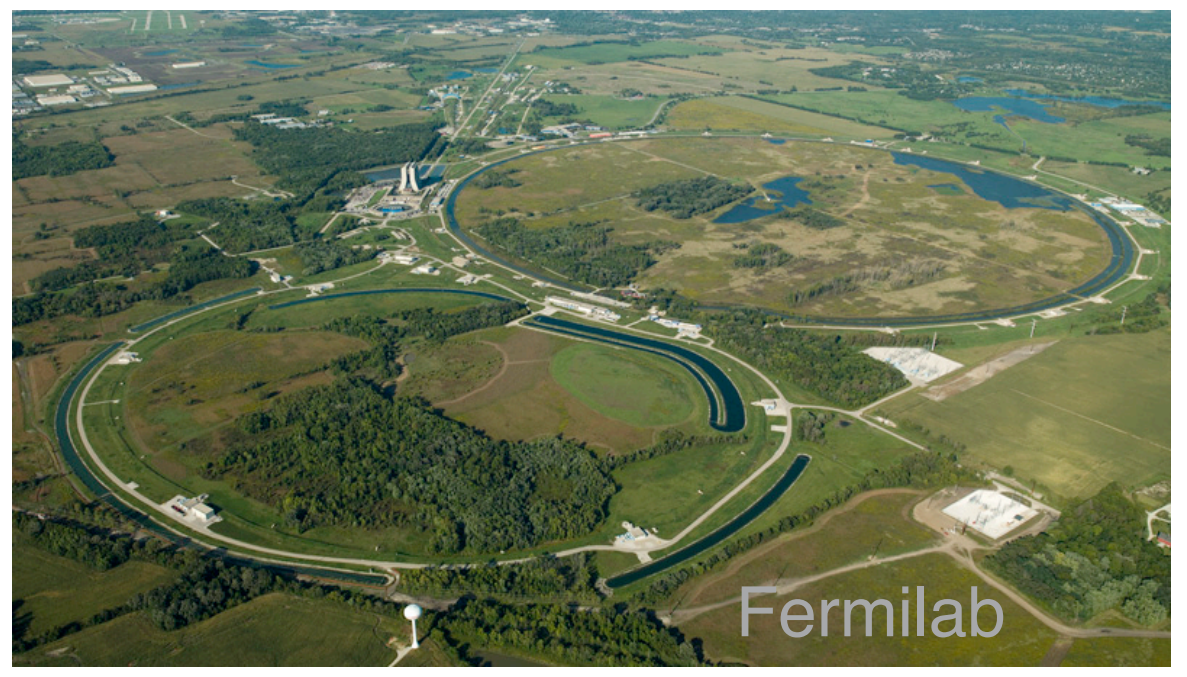

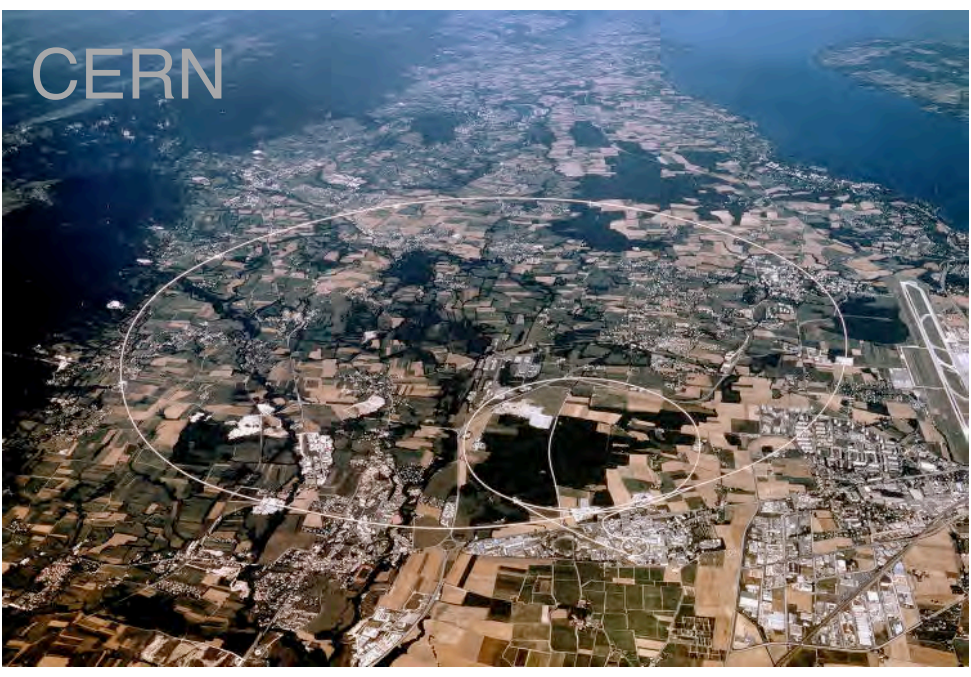

Incontri di Fisica 2020 INFN/LNF 6 novembre 2020 


\section{Quali saranno le prossime tappe fondamentali?}

- Ricerche attive in diversi campi:

- produzione e stabilizzazione di fasci ultra-intensi per la fisica dei neutrini e dei processi rari

- nuove tecniche di raffreddamento per aumentare la densità dei fasci negli anelli di collisione

- accelerazione nei plasmi eccitati da fasci primari o laser

$\bullet . .$.
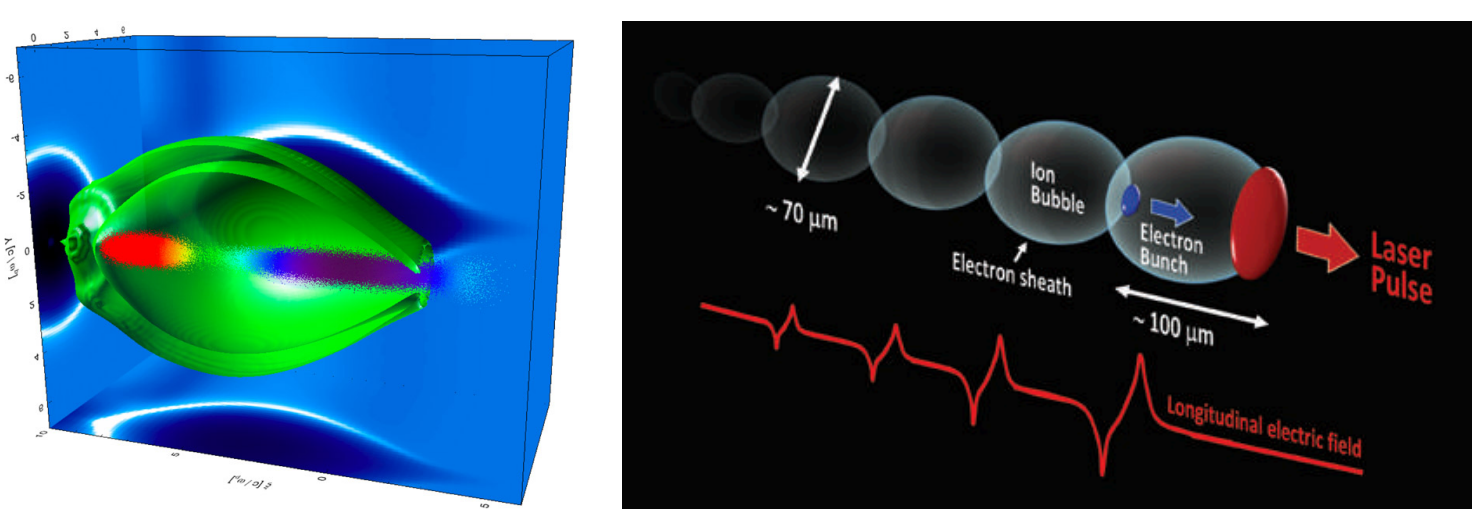
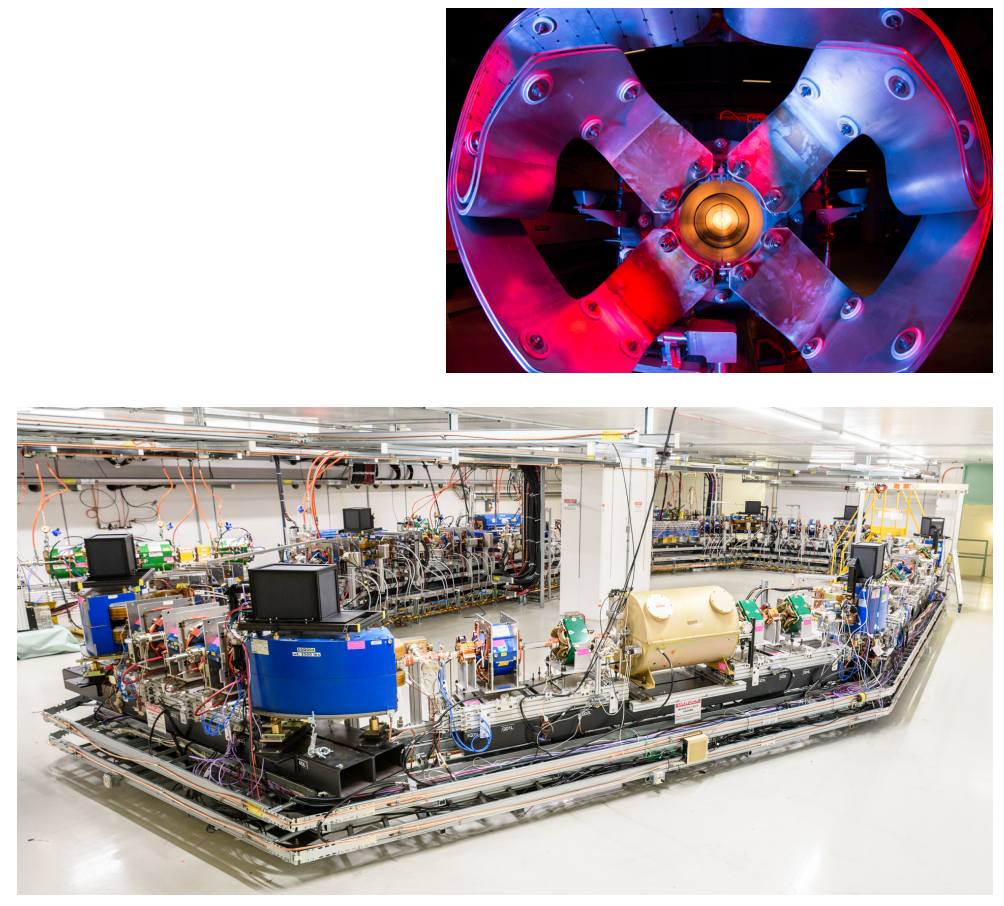

MICE Muon lonization

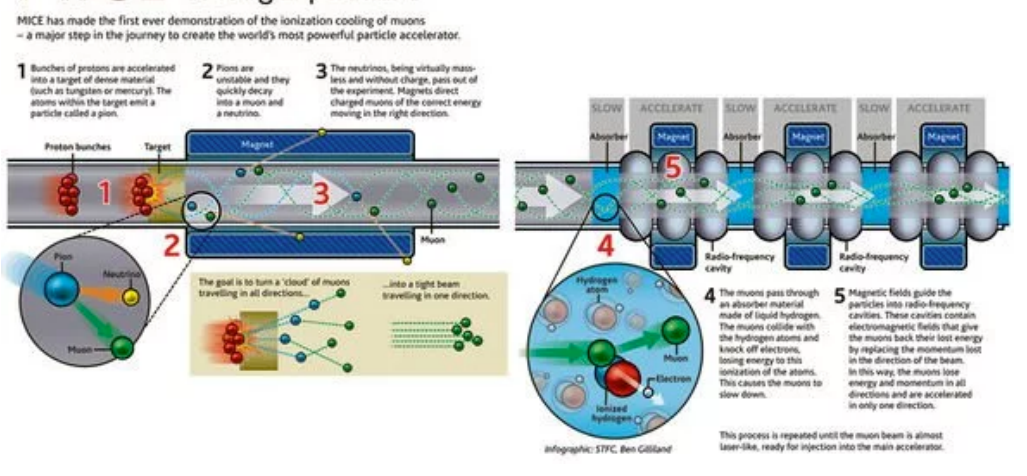


Applicazioni degli acceleratori 


\section{A cosa servono gli acceleratori?}

- Fisica nucleare e fisica delle particelle elementari

- creazione di nuove forme di materia, studio delle forze fondamentali

- Biologia, chimica, scienza dei materiali

- struttura e dinamica di sistemi microscopici con radiazione di sincrotrone, FEL ("free-electron lasers"), sorgenti di neutroni...

- Medicina

- radioterapia, adroterapia, produzione di isotopi per la diagnostica, sterilizzazione, ...

- Archeologia e arte

- datazione con ${ }^{14} \mathrm{C}$, analisi sensibili di piccoli campioni, ... 


\section{A cosa servono gli acceleratori?}

- Processi industriali

- impiantazione ionica nei semiconduttori, micro-litografia, sterilizzazione dei cibi, polimerizzazione, trattamento materiali, ...

- Difesa

- rivelazione di carichi illeciti, neutralizzazione pacchi sospetti, ...

- Energia e ambiente

- attivazione reattori nucleari a fissione (ADS), fusione nucleare, trattamento di rifiuti e scorie radioattive, ...

La maggior parte delle decine di migliaia di acceleratori esistenti è utilizzata nell'industria e in medicina. 


\section{Sorgenti di luce di sincrotrone}

Particelle cariche accelerate emettono radiazione elettromagnetica
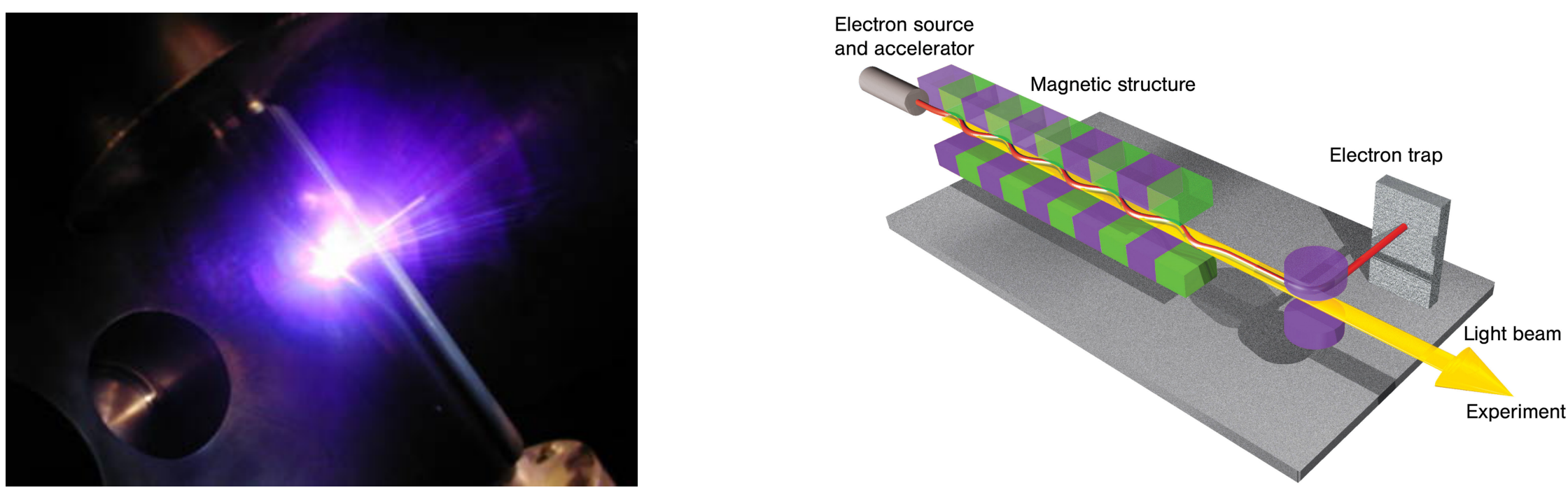

Spesso chiamata "luce di sincrotrone" dopo le prime osservazioni con fasci di elettroni in sincrotrone

Negli acceleratori:

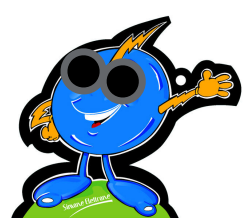

- l'energia persa deve essere ripristinata dalle cavità acceleranti (svantaggio)

- l'effetto combinato di emissione di radiazione e forze esterne crea un addensamento delle particelle o "raffreddamento" (vantaggio) 


\section{Sorgenti di luce di sincrotrone}

Sincrotroni per elettroni e FEL generano radiazione con proprietà uniche
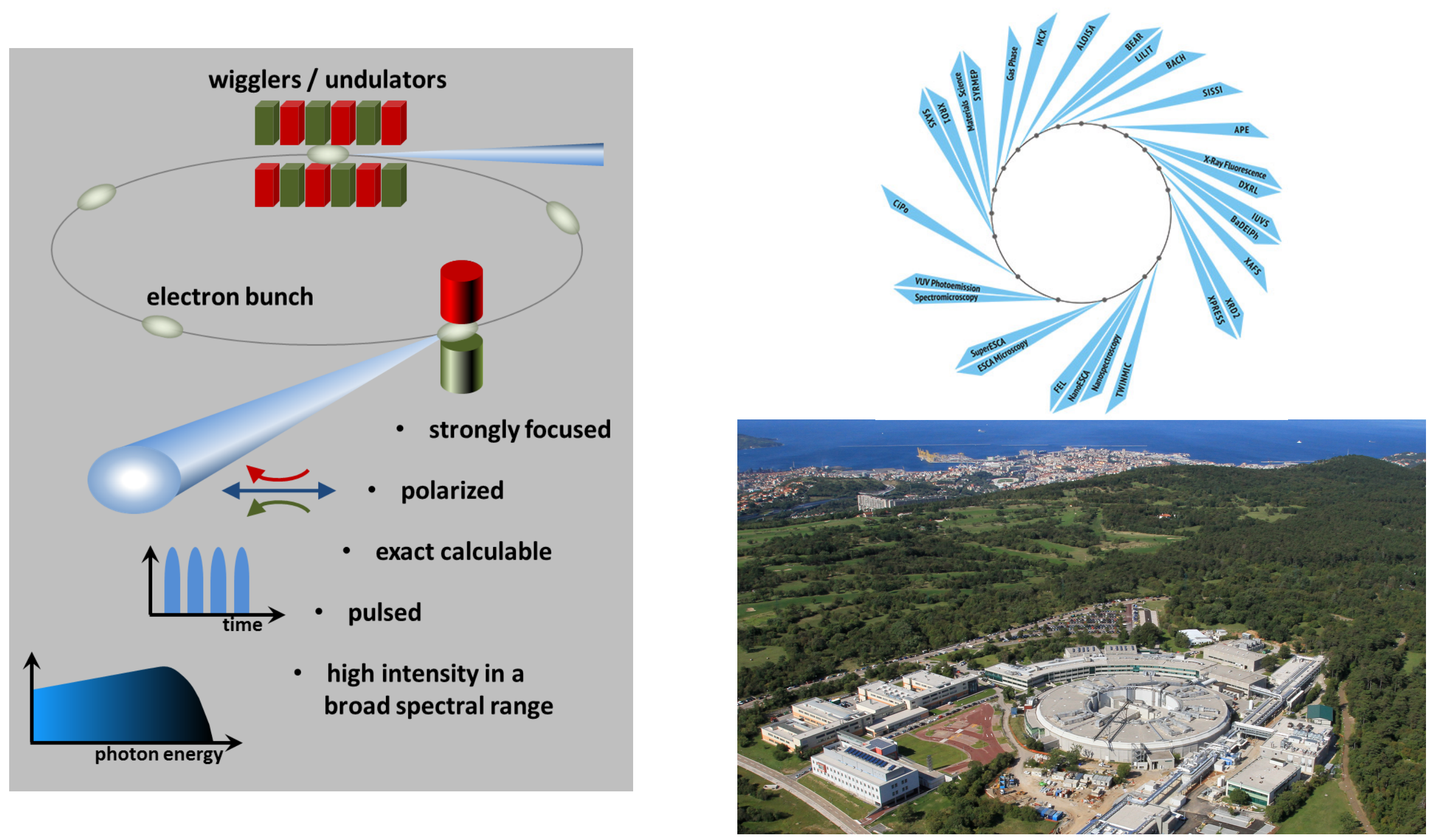

Elettra (sincrotrone) e FERMI (laser a elettroni liberi) a Trieste 


\section{Numerosissime applicazioni della luce di sincrotrone}

Decine di laboratori nel mondo sono dedicati alla biologia, medicina, chimica, fisica e scienza dei materiali

\section{struttura di macromolecole (diversi premi Nobel)}

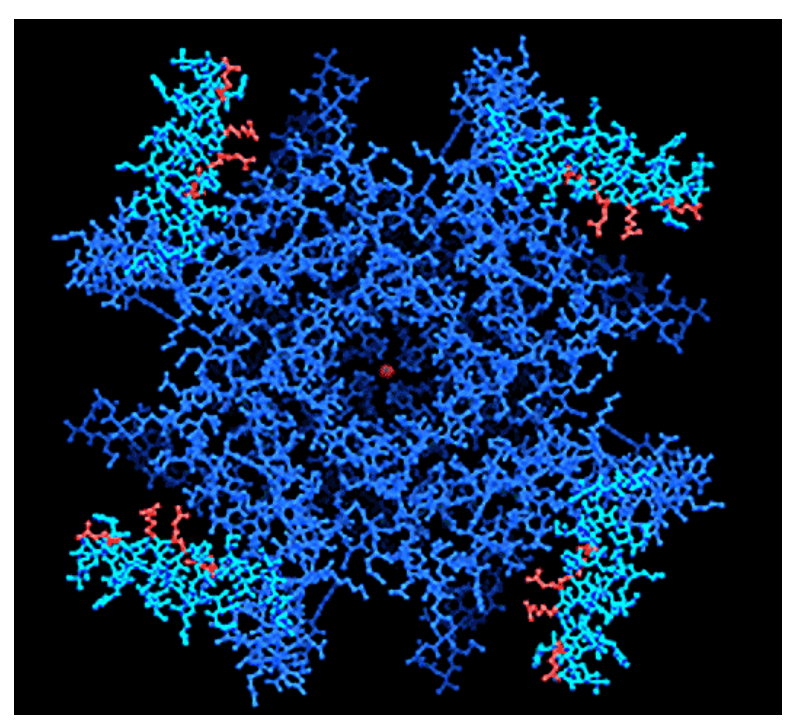

lightsources.org
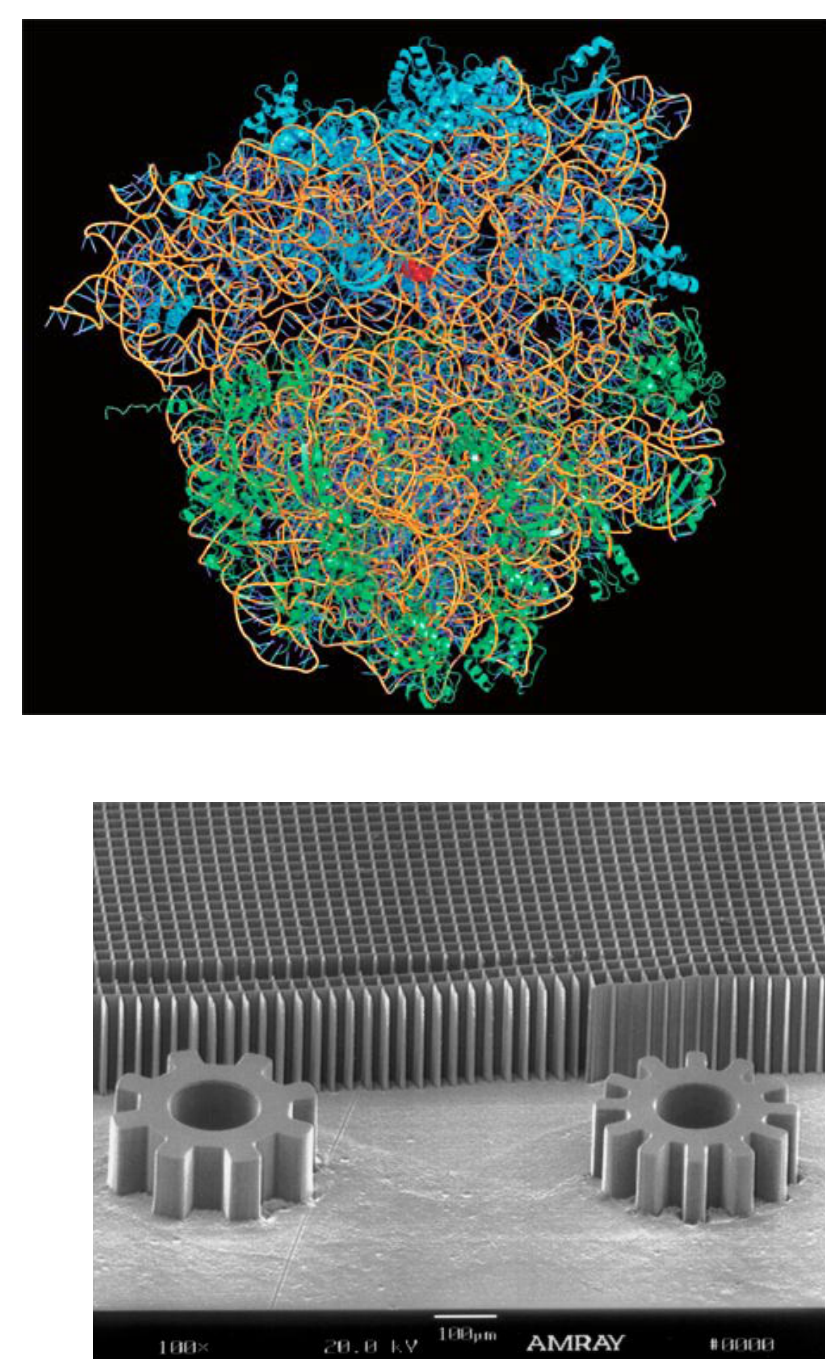

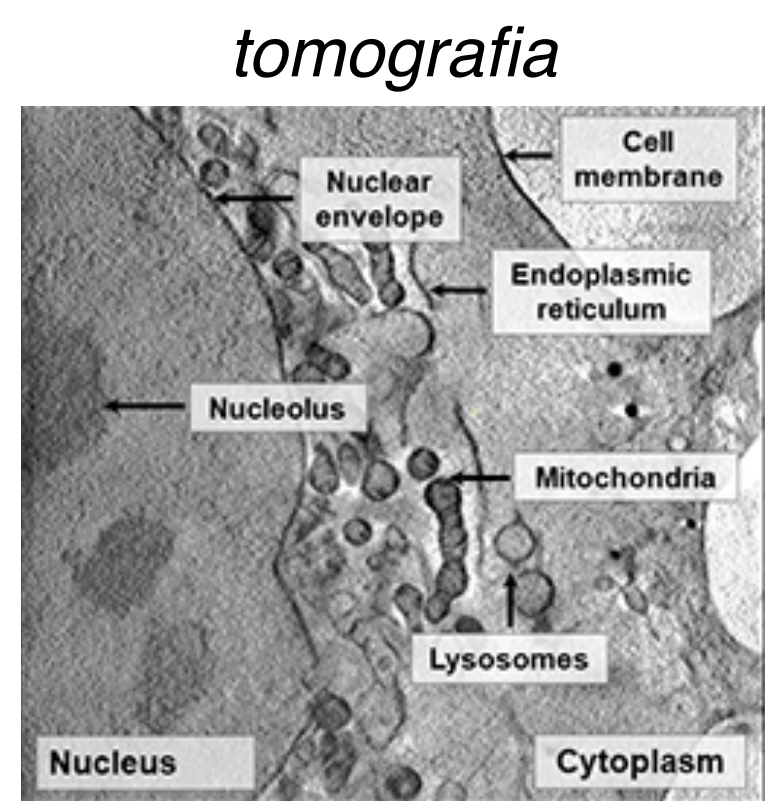

litografia 


\section{Acceleratori per la terapia dei tumori}

- Le radiazioni ionizzanti sono fotoni, elettroni, protoni, ioni, neutroni, ecc. con sufficiente energia per liberare elettroni dalle molecole

- La quantità totale di energia depositata è detta dose

- La terapia dei tumori si basa sull'effetto delle radiazioni ionizzanti sul DNA

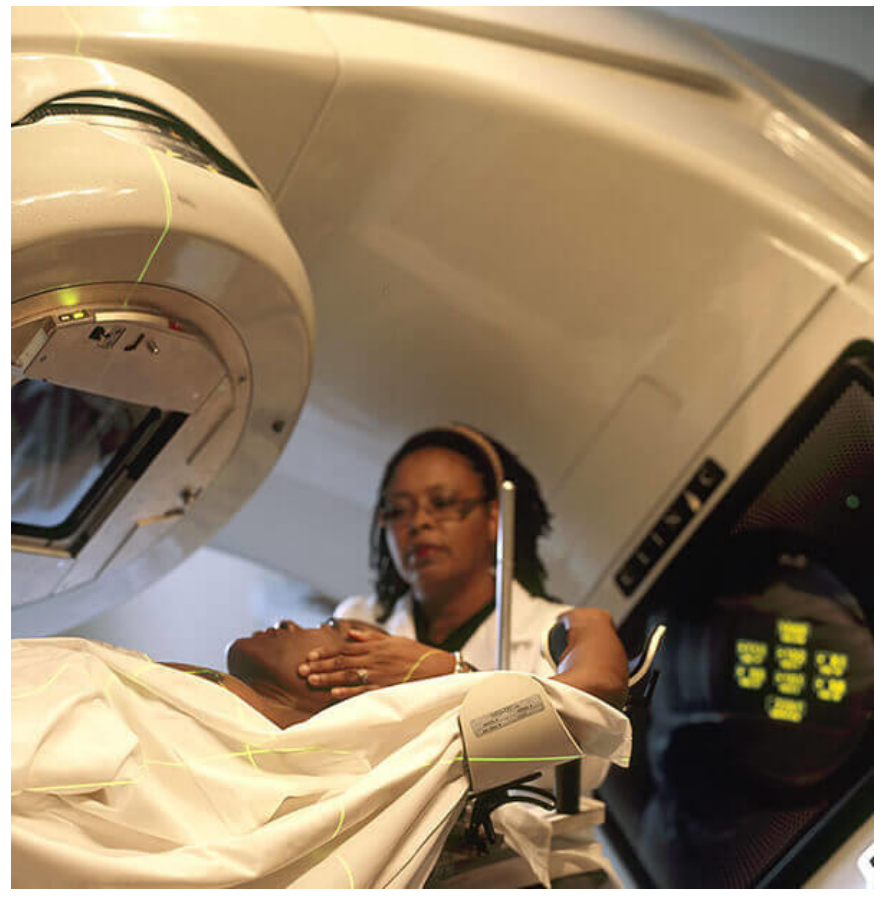

- Spesso le cellule cancerose sono più vulnerabili di quelle sane: finestra terapeutica 


\section{Energia depositata nei tessuti: radioterapia e adroterapia}

Ciascun tipo di radiazione ha un suo caratteristico effetto sui tessuti
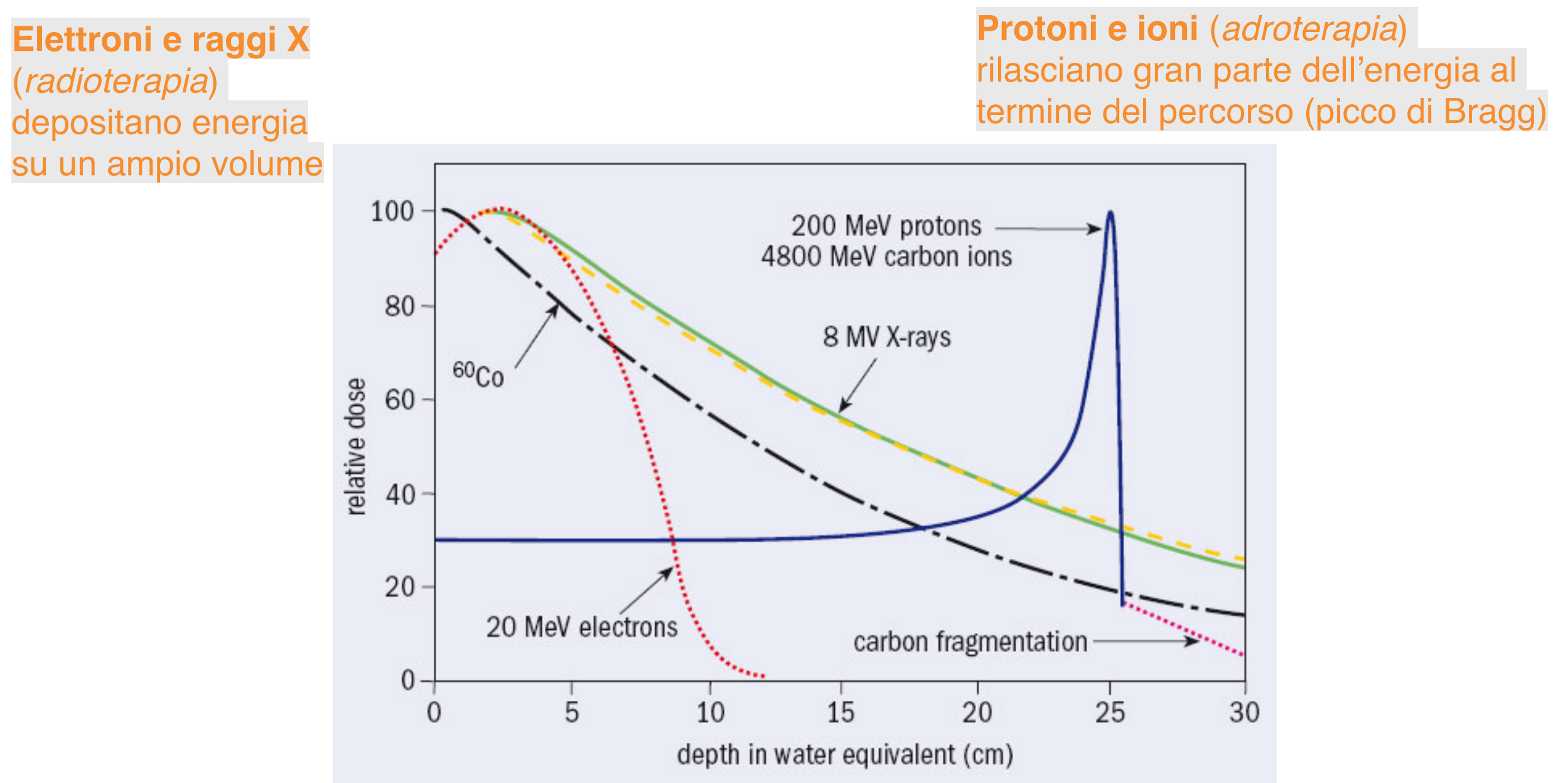

L'energia del fascio primario determina la profondità di penetrazione. Ad esempio, sono necessari protoni da $200 \mathrm{MeV}$ per raggiungere profondità di $25 \mathrm{~cm}$ 


\section{Acceleratori per radioterapia e adroterapia}

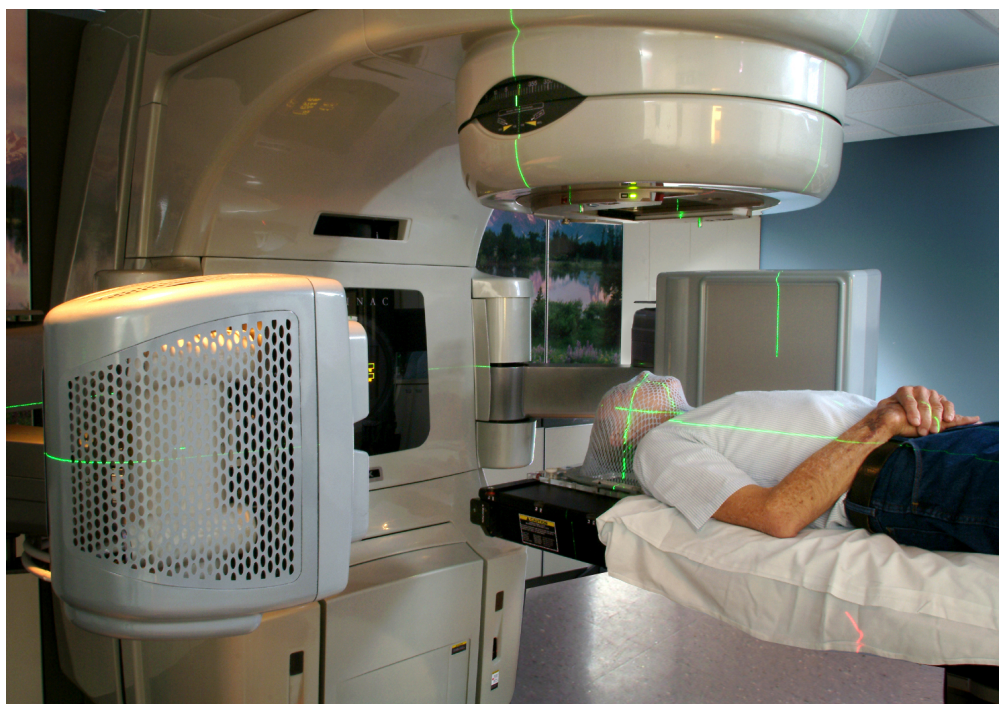

Sistema radioterapico prodotto dalla Varian

Protoni e ioni carbonio richiedono sincrotroni per raggiungere le prestazioni necessarie
Elettroni e raggi $X$ vengono prodotti con linac compatti

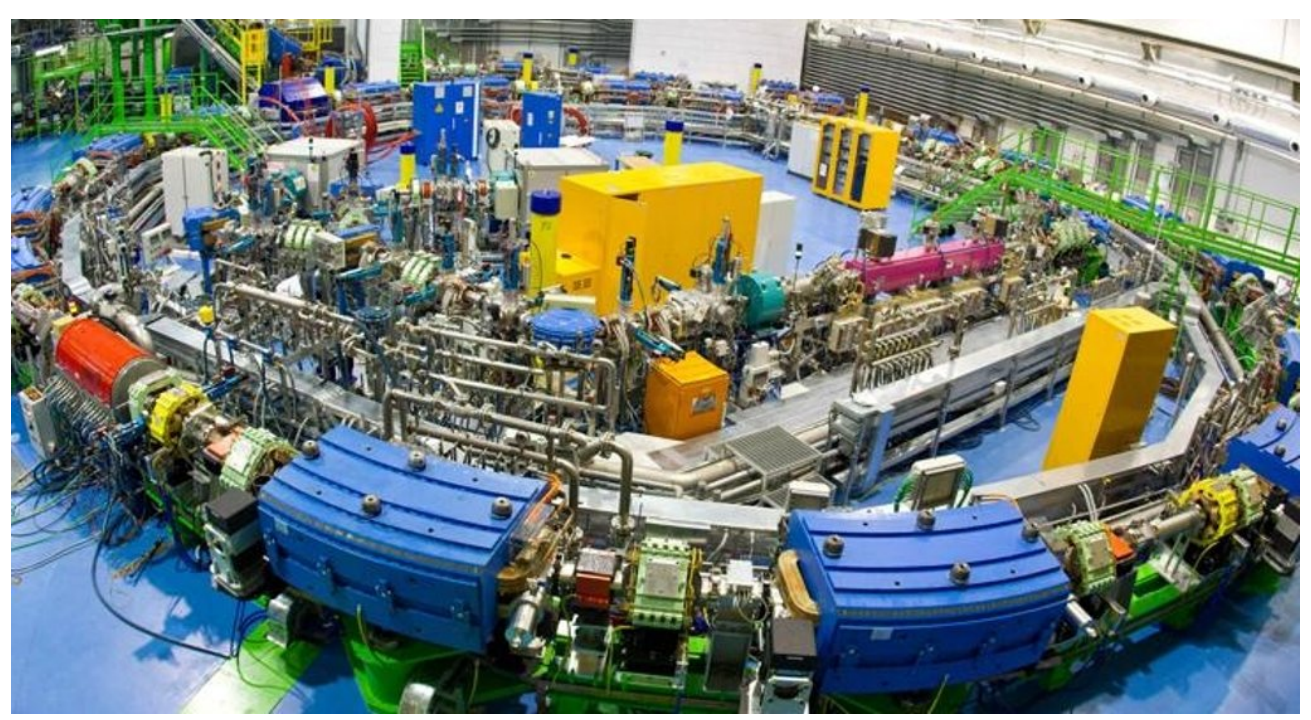

Il sincrotrone del CNAO di Pavia 


\section{Un acceleratore al Louvre dedicato alle belle arti}

AGLAE (Accélérateur Grand Louvre d'Analyse Élémentaire)
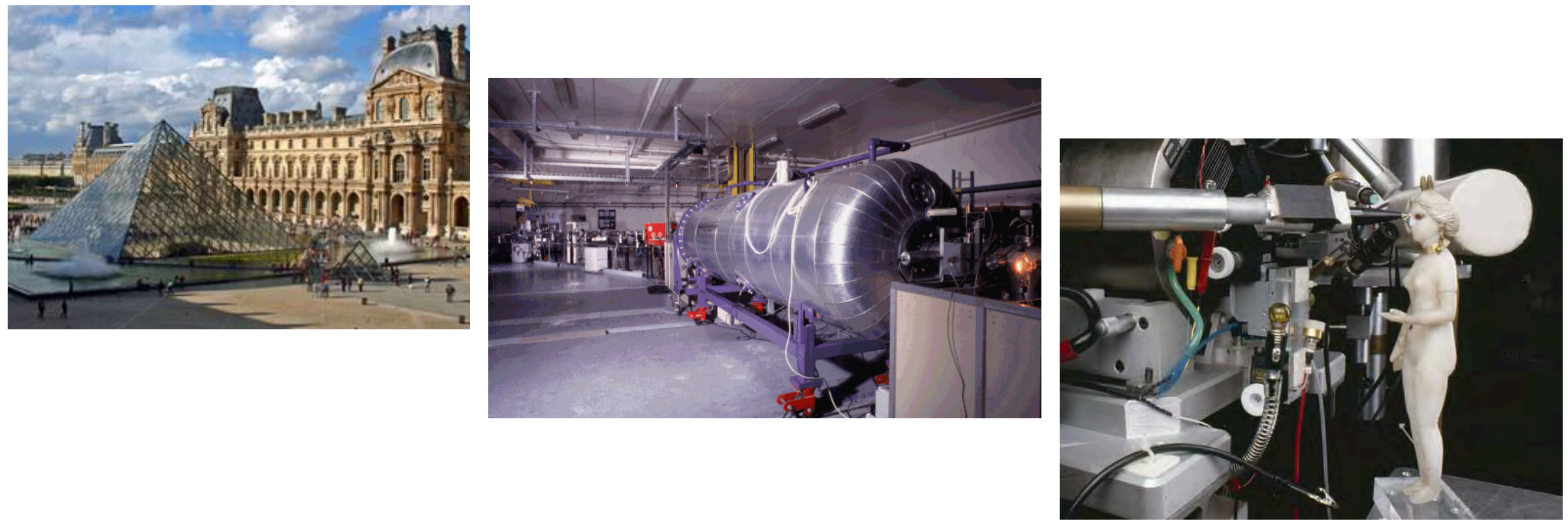

Analisi dei materiali con fascio di ioni (spettri dei raggi X, gamma e dei protoni diffusi) per determinare età, tecniche utilizzate e provenienza delle opere custodite in varie istituzioni culturali 


\section{Acceleratori di elettroni creano sculture e fotografie}

Shockfossils (figure di Lichtenberg) di Todd Johnson (Fermilab), "fulmini congelati" creati con lastre di acrilico caricate elettricamente da un acceleratore industriale e sottoposte a scarica elettrica improvvisa

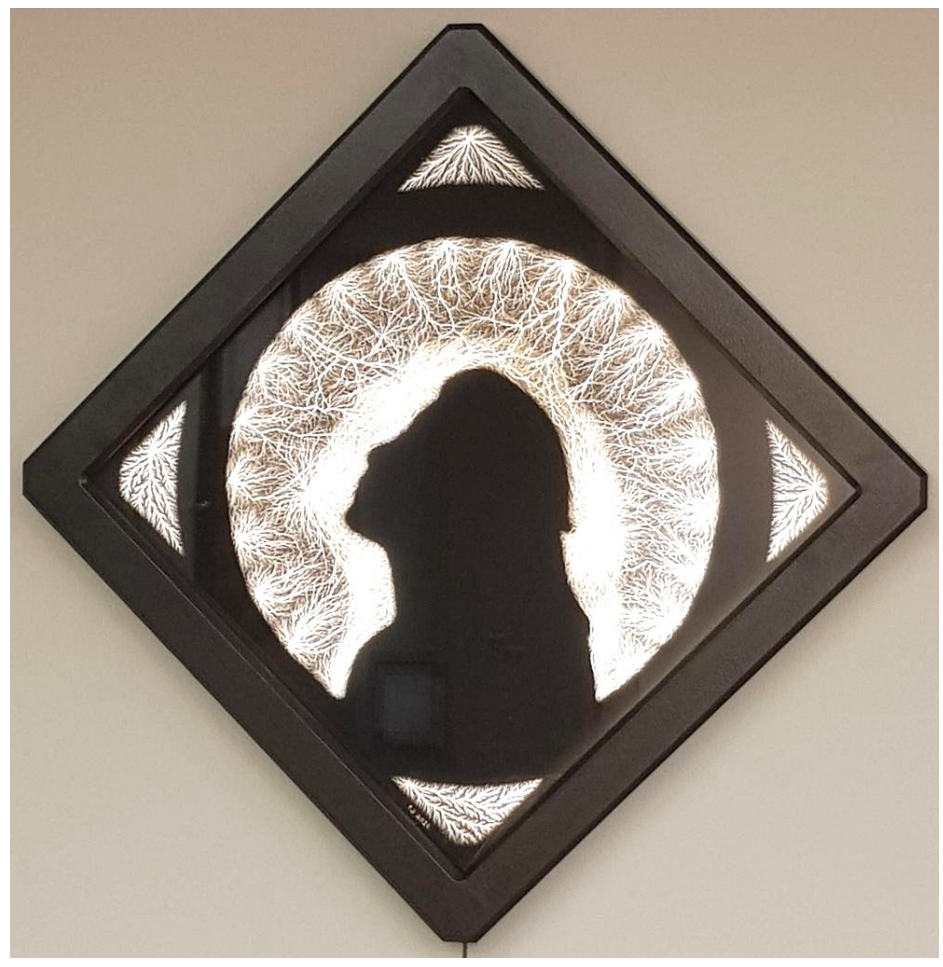

II fotografo Adam Nadel usa elettroni dalla macchina A2D2 a Fermilab (invece della luce) per creare immagini astratte

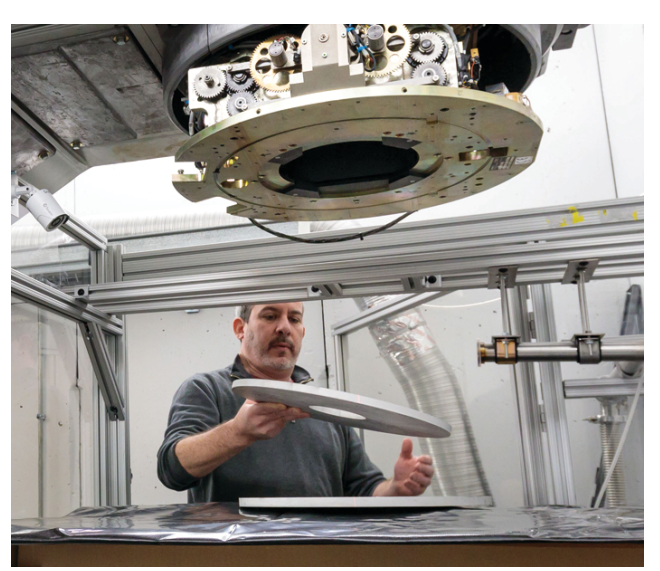

su pellicola fotografica

"Every science begins as philosophy and ends as art." -Will Durant 


\section{Spunti per la didattica}




\section{Idee per progetti didattici}

- Approfondire una scoperta resa possibile dagli acceleratori di particelle: Qual è la rilevanza per la storia della scienza? Com'è stato progettato l'esperimento? Quali strumenti sono stati utilizzati? Quali conclusioni si possono trarre? Quali domande rimangono ancora aperte?

- Approfondire un'applicazione degli acceleratori: Qual è la rilevanza per la società? Quali tecnologie e soluzioni sono state sviluppate? Quali problemi rimangono insoluti?

- Approfondire l'aspetto storico e umano degli sviluppi scientifici: Contesto storico, aneddoti, biografie 


\section{Idee per progetti didattici}

- Analogia tra ottica geometrica e focalizzazione di particelle cariche: Quali sono gli aspetti simili? Quali sono le differenze? Come cambiano i concetti principali? Raggi, lenti, lunghezza focale, matrici di trasporto, aberrazioni cromatiche, ...

- Il ruolo dell'oscillatore armonico in fisica: meccanica classica, elettromagnetismo, meccanica quantistica, ...

- Analogia tra il moto di una carica in un condensatore e in un campo gravitazionale. Cosa cambia nel diodo limitato dalla densità di carica? ("Oscillatore armonico" della fisica dei fasci di particelle.)

- Introduzione ai sistemi dinamici non lineari e alla fisica del caos. Cosa significa "comprendere" un fenomeno fisico? Che differenza c'è tra conoscere le equazioni e fare previsioni? Come si applica la teoria dei sistemi dinamici a fenomeni reali? 
Risorse 


\section{Libri, riviste, siti Internet}

- Rivista Asimmetrie dell'INFN, numero sugli acceleratori (4/2008)

- Sessler e Wilson, Engines of Discovery (World Scientific)

- Segré, Personaggi e scoperte della fisica contemporanea (Mondadori)

- Bernardini, Fisica vissuta (Codice)

- Amaldi, La fisica del caos (Zanichelli)

- Gleick, Caos (Sansoni)

- Segré, Nuclei e particelle (Zanichelli)

- CERN Beamline for Schools, beamlineforschools.cern

- CERN Accelerator School, cas.web.cern.ch

- US Particle Accelerator School, uspas.fnal.gov 


\section{Contatti}

- Il mio sito Internet a Fermilab

- home.fnal.gov/ stancari

- Corso introduttivo sugli acceleratori per laureandi e dottorandi, Università di Ferrara (2019)

- bitbucket.org/gist/apufe19 


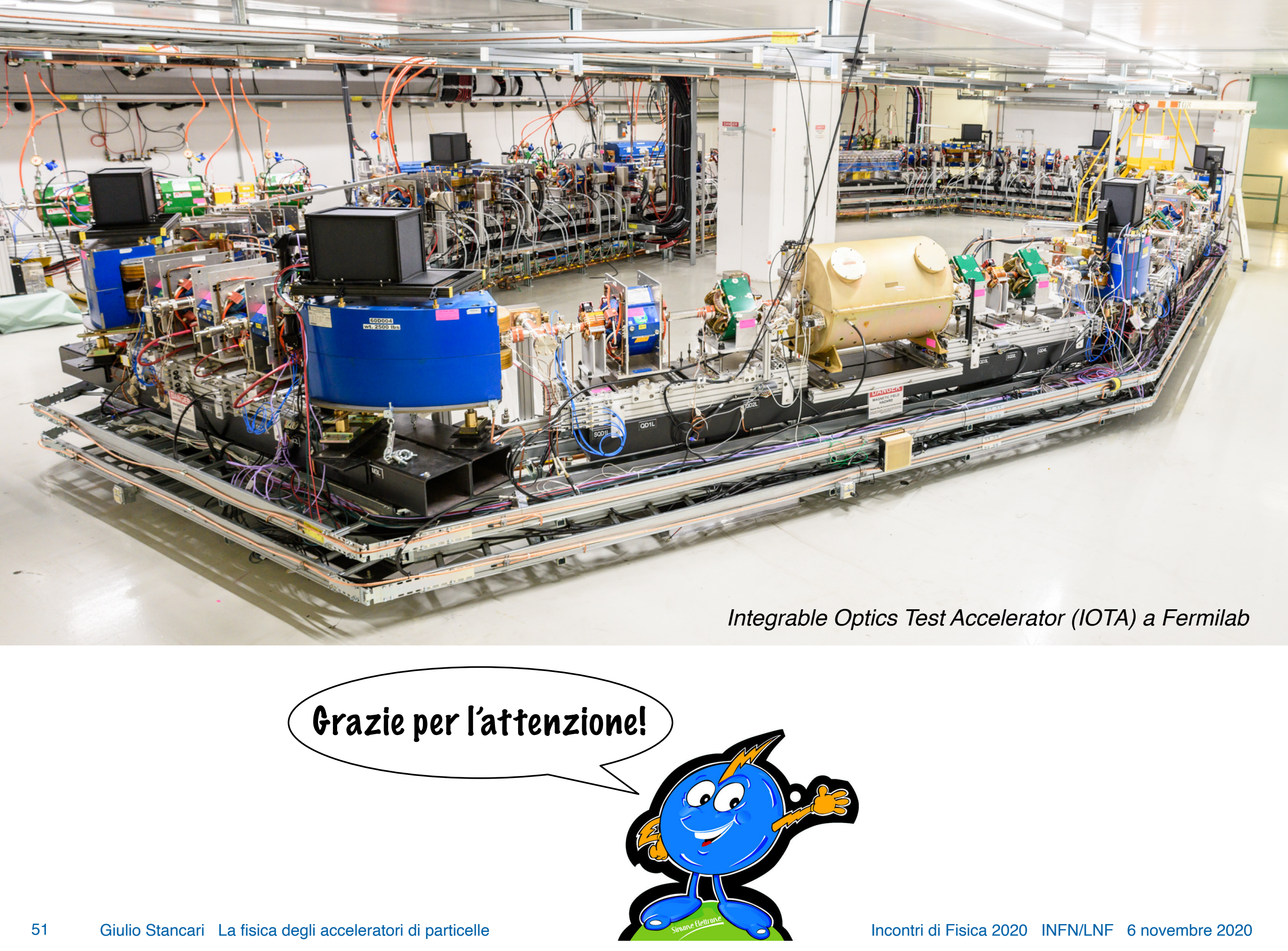

